\title{
Plant Extracts in the Bone Repair Process: A Systematic Review
}

\author{
Lyvia Lopes Miranda, ${ }^{1}$ Vanessa de Paula Guimarães-Lopes, ${ }^{2}$ Luciana Schulthais Altoé, ${ }^{1}$ \\ Mariáurea Matias Sarandy $\mathbb{D}^{2}{ }^{2}$ Fabiana Cristina Silveira Alves Melo $\mathbb{D}^{2}{ }^{2}$ \\ Rômulo Dias Novaes $\mathbb{I D}^{3}$ and Reggiani Vilela Gonçalves $\mathbb{i D}^{2}$
}

\author{
${ }^{1}$ Department of General Biology, Federal University of Viçosa, Viçosa, Minas Gerais 36570-900, Brazil \\ ${ }^{2}$ Department of Animal Biology, Federal University of Viçosa, Viçosa, Minas Gerais 36570-900, Brazil \\ ${ }^{3}$ Institute of Biomedical Sciences, Department of Structural Biology, Federal University of Alfenas, Alfenas, \\ Minas Gerais 37130-001, Brazil
}

Correspondence should be addressed to Reggiani Vilela Gonçalves; reggysvilela@yahoo.com.br

Received 3 July 2019; Revised 1 October 2019; Accepted 11 October 2019; Published 25 November 2019

Academic Editor: Joilson O. Martins

Copyright ( 2019 Lyvia Lopes Miranda et al. This is an open access article distributed under the Creative Commons Attribution License, which permits unrestricted use, distribution, and reproduction in any medium, provided the original work is properly cited.

\begin{abstract}
Bone lesions are an important public health problem, with high socioeconomic costs. Bone tissue repair is coordinated by an inflammatory dynamic process mediated by osteoprogenitor cells of the periosteum and endosteum, responsible for the formation of a new bone matrix. Studies using antioxidant products from plants for bone lesion treatment have been growing worldwide. We developed a systematic review to compile the results of works with animal models investigating the anti-inflammatory activity of plant extracts in the treatment of bone lesions and analyze the methodological quality of the studies on this subject. Studies were selected in the PubMed/MEDLINE, Scopus, and Web of Science databases according to the PRISMA statement. The research filters were constructed using three parameters: animal model, bone repair, and plant extracts. 31 full-text articles were recovered from 10 countries. Phytochemical prospecting was reported in 15 studies (48.39\%). The most common secondary metabolites were flavonoids, cited in $32.26 \%$ studies $(n=10)$. Essential criteria to in vivo animal studies were frequently underreported, suggesting publication bias. The animals treated with plant extracts presented positive results in the osteoblastic proliferation, and consequently, this treatment accelerated osteogenic differentiation and bone callus formation, as well as bone fracture repair. Possibly, these results are associated with antioxidant, regenerative, and anti-inflammatory power of the extracts. The absence or incomplete characterization of the animal models, treatment protocols, and phytochemical and toxicity analyses impairs the internal validity of the evidence, making it difficult to determine the effectiveness and safety of plant-derived products in bone repair.
\end{abstract}

\section{Introduction}

Bone lesions are an important health problem, causing social and financial burden [1]. It is estimated that, with the increase in the elderly population in the world, the incidence of fractures increases even more in the next years [2]. In 2015 , costs for fracture treatments were about $\$ 17.8$ billion, and by 2025 , annual costs are expected to exceed $\$ 25$ billion each year in the United States [3]. Bone remodeling is composed of a complex sequence of cellular events [4] that include phases of inflammation, cell proliferation, and bone remodeling, which is controlled by osteogenesis and angio- genesis [5]. In most cases, bone fractures are caused by specific bone traumas or diseases [6].

The bone has high capacity of remodeling, being able to regenerate and maintain its structure and function. However, there are clinical situations in which the acceleration of bone formation is desirable [7]. Research has been carried out to better understand the inflammatory mechanisms that regulate this repair process and identify new therapeutic targets for the treatment of bone fractures $[8,9]$. In this context, natural products, biomaterials, and their derivatives have stood out as a promising alternative to minimize side effects, reduce costs, and promote a fast and efficient repair process [10]. 
Drugs derived from medicinal plants are consumed by about $75 \%$ of the world's population [11] and represent the main form of treatment for traditional medicine in the majority of developing nations [12]. Studies have shown that some molecules extracted from natural compounds have high anti-inflammatory, antioxidant, and regenerative effects, which justifies the successful use of these products in different diseases [13]. However, the mechanisms by which compounds of natural origin act in the inflammatory process and consequently in bone healing are still poorly understood. Current evidences are sparse, fragmented, and based on punctual researches, which makes the results described in the literature inconsistent. Although not clear, we believe that the action of the plant extracts is related to the increase in the antioxidant defenses and decreased tissue inflammation, as well as the increase in the vascularization of the tissue and proliferative activity of the bone cells.

Clinical and preclinical studies have attempted to demonstrate the positive effects of plant compounds on bone matrix formation and cellular activity $[14,15]$. However, this proposition is not always confirmed, mainly due to the great methodological variations involving the extract preparation, therapeutic schemes, and mechanisms of action [16]. Therefore, it is necessary to compile data from several studies in order to clarify the previous discrepancies. In this context, we systematically analyzed the preclinical evidence in vivo, to establish the relevance of the use of vegetal products in bone repair. In addition, we aimed to determine if there is a rational selection criterion of the plant species to be used and the geographic distribution of each species, as well as any evidence of bioprospection based on ethnobotanical data. We also performed a critical analysis of the studies, aiming to improve the quality of the reports, preventing the reproduction of methodological failures in new studies.

\section{Materials and Methods}

2.1. Search Strategy. The PRISMA (Preferred Reporting Items for Systematic Reviews and Meta-Analyses) strategy was applied to identify all studies included in this review [17]. A direct search was carried out from three comprehensive electronic databases: PubMed/MEDLINE, Scopus, and Web of Science. The secondary search was based on the screening of the reference list of all relevant studies identified in the direct search.

Structured search filters were developed for each database. The search filters were initially constructed considering standardized descriptors extracted from PubMed thesaurus (MeSH (Medical Subject Headings)). All descriptors were combined in a complete three-level search strategy based on (i) animal model, (ii) bone repair, and (iii) plant extracts. Standardized descriptors were defined by the MeSH algorithm, and non-MeSH descriptors were characterized by the TIAB algorithm which was also used to recover recently published studies and studies in process for indexation. A previously published and optimized animal filter was applied in a PubMed search interface [18]. The same search filters used for bone repair and intervention were adapted for Scopus. The Scopus' own animal filter (keyword-animals [limit to]) was used in this database. Only studies in English, Portuguese, and Spanish were recovered, and no chronological limits were applied in our search strategy (Table S1). All relevant studies published until September 10, 2019 (updated search date), were recovered and included in the systematic review.

2.2. Record Screening and Eligibility. All research records recovered in the database search were analyzed, and duplicates were removed considering the authors, title, journal, and year of publication. After title and abstract screening, all potentially relevant studies were evaluated in full text for eligibility according to specific inclusion and exclusion criteria. Only original studies investigating the relevance of plant extracts on bone repair in preclinical studies with animal models were included. The exclusion criteria were based on the following: (i) it is not bone, (ii) it is not a plant extract, (iii) laminectomy, (iv) absence of bone defect, (v) peptides and fractions obtained from plants, (vi) compounds obtained from animals, (vii) in vitro, (viii) secondary studies (literature reviews, letters to the editor, case studies, comments, and editorials), (ix) marketed products, (x) associated treatment (treatment with plant extracts associated with the other plants and other compounds such as collagen matrix, laser, physical activity, and commercial drugs), (xi) other language, and (xii) bone marrow. Eligibility was independently analyzed by the researchers, and disagreements were resolved by consensus. In order to enhance the comprehension of the research strategy, the reference lists of all relevant papers identified from the database search were screened for additional studies.

2.3. Data Extraction. An initial selection based on the title and abstract (TIAB) was conducted by three independent reviewers. In case of disagreements, a fourth reviewer (RVG) decided whether the study met the inclusion and exclusion criteria. In order to discard subjectivity in the data collection and selection strategy, the information was independently extracted by the four reviewers (LLM, LSA, MMS, and RVG) and analyzed separately.

Data were extracted and tabulated in a descriptive way (tables of descriptors and results). The data extraction was categorized as follows: (I) characteristics of publication: author, year, and country; (II) characteristics of the animal model: species, sex, age, and weight; (III) treatment characteristics: total number of animals, number of animals in each group, control group, treatment time, osteoporosis induction, bone type, bone defect model, lesion size, anesthetics, and euthanasia procedure; and (IV) plants: species, used part, popular indication, extraction and purification method, dose, administration, secondary metabolites, and geographical distribution.

2.4. Methodological Bias. Reporting bias was analyzed based on methodological requirements described in the ARRIVE (Animal Research: Reporting of In Vivo Experiments) guideline [19]. This strategy requires the complete screening of all manuscript sessions (abstract to acknowledgements and funding) to evaluate the completeness of the scientific reports 


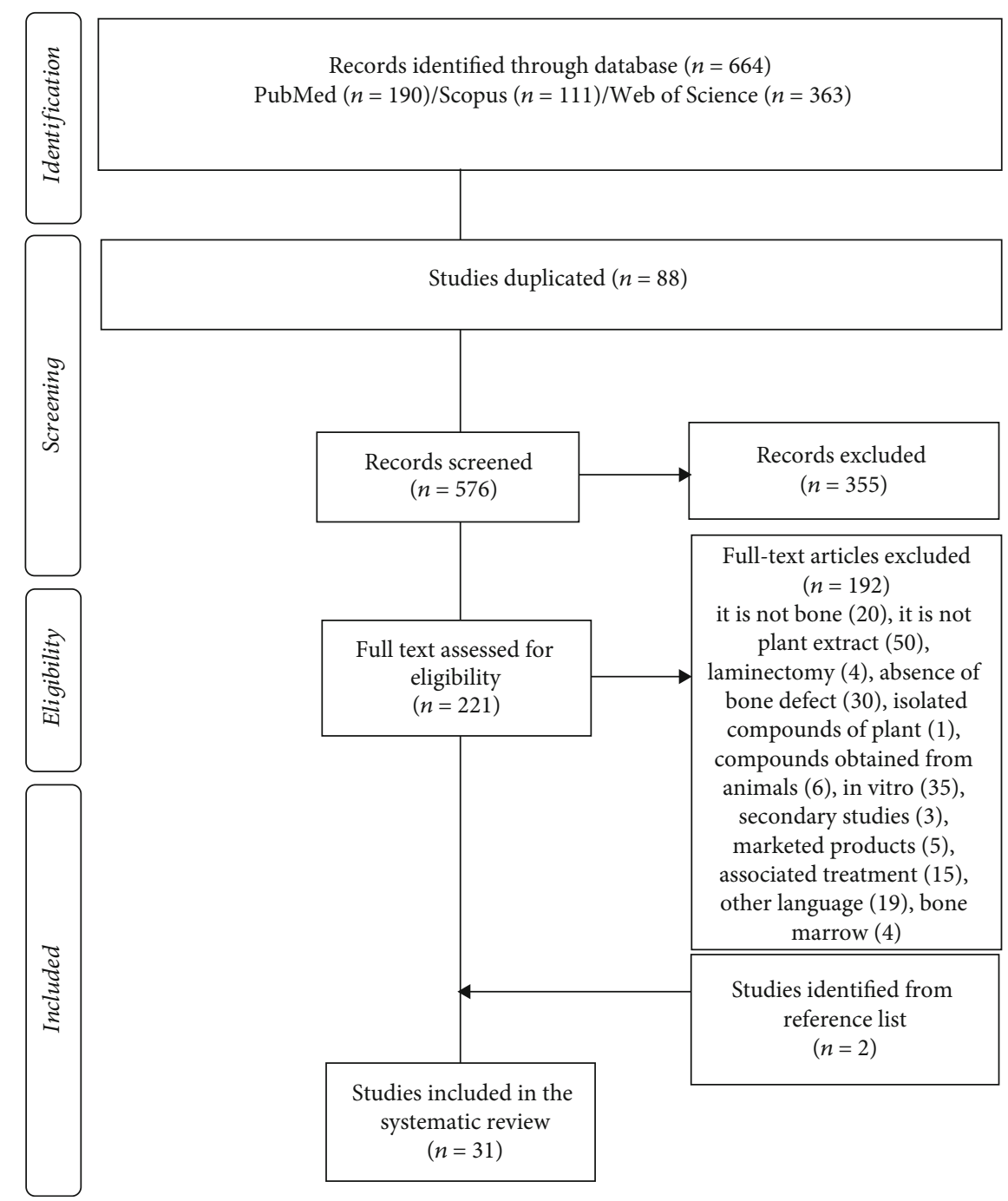

FIGURE 1: PRISMA diagram. Different phases of selection of studies for conducting qualitative and quantitative analyses. Flow diagram of the systematic review literature search results. Based on "Preferred Reporting Items for Systematic Reviews and Meta-Analyses: The PRISMA Statement" (http://www.prisma-statement.org) [17].

in animal studies. The screening strategy was based on short descriptions of essential characteristics such as baseline measurements, sample size, animal allocation, randomization, experimental concealment, statistical methods, ethnical statement, and generalizability power. A table summarizing all relevant and applicable aspects was designed considering the specificity and aims of the systematic review.

\section{Results}

3.1. PRISMA Guideline. From the PubMed/MEDLINE, Scopus, and Web of Science databases, 664 articles were recovered. A total of 88 duplicated studies and 528 with inadequate thematic were excluded after reading the title and abstract. Of the 48 remaining studies, 19 articles were excluded after reading the full text for not meeting the eligibility criteria. Therefore, 29 studies were included in the systematic review. The reference list of all included studies was analyzed to ensure the identification of additional relevant studies, and 2 of them were recovered, totalizing 31 studies. Figure 1 shows the flowchart and each step performed in the selection process to recover relevant studies.

3.2. Qualitative Analysis. The general characteristics of all included studies are shown in Table 1. The analyzed studies were conducted in 10 different countries especially India (25.81\%, $n=8)$, followed by China and Brazil (16.13\%, $n=5$ each), Cameroon and Turkey $(9.68 \%, n=3$ each), and Germany $(6.45 \%, n=2)$. The most commonly used animal models were murine $(80.64 \%, n=25)$ and rabbits $(19.35 \%, n=6)$. Considering the animal strain, $51.61 \%$ $(n=16)$ were Sprague-Dawley rats; $22.58 \%(n=7)$, Wistar rats; and $19.35 \%(n=6)$, New Zealand white rabbits, followed by rats and mice $(6.45 \%, n=2$ each). From the experimental models, $51.61 \%(n=16)$ used female animals, $32.26 \%$ $(n=10)$ used males, $3.22 \%(n=1)$ used both sexes, and $12.90 \%(n=4)$ of all studies did not report this information. The animals' age ranged from 7 weeks to 6 months for rats 


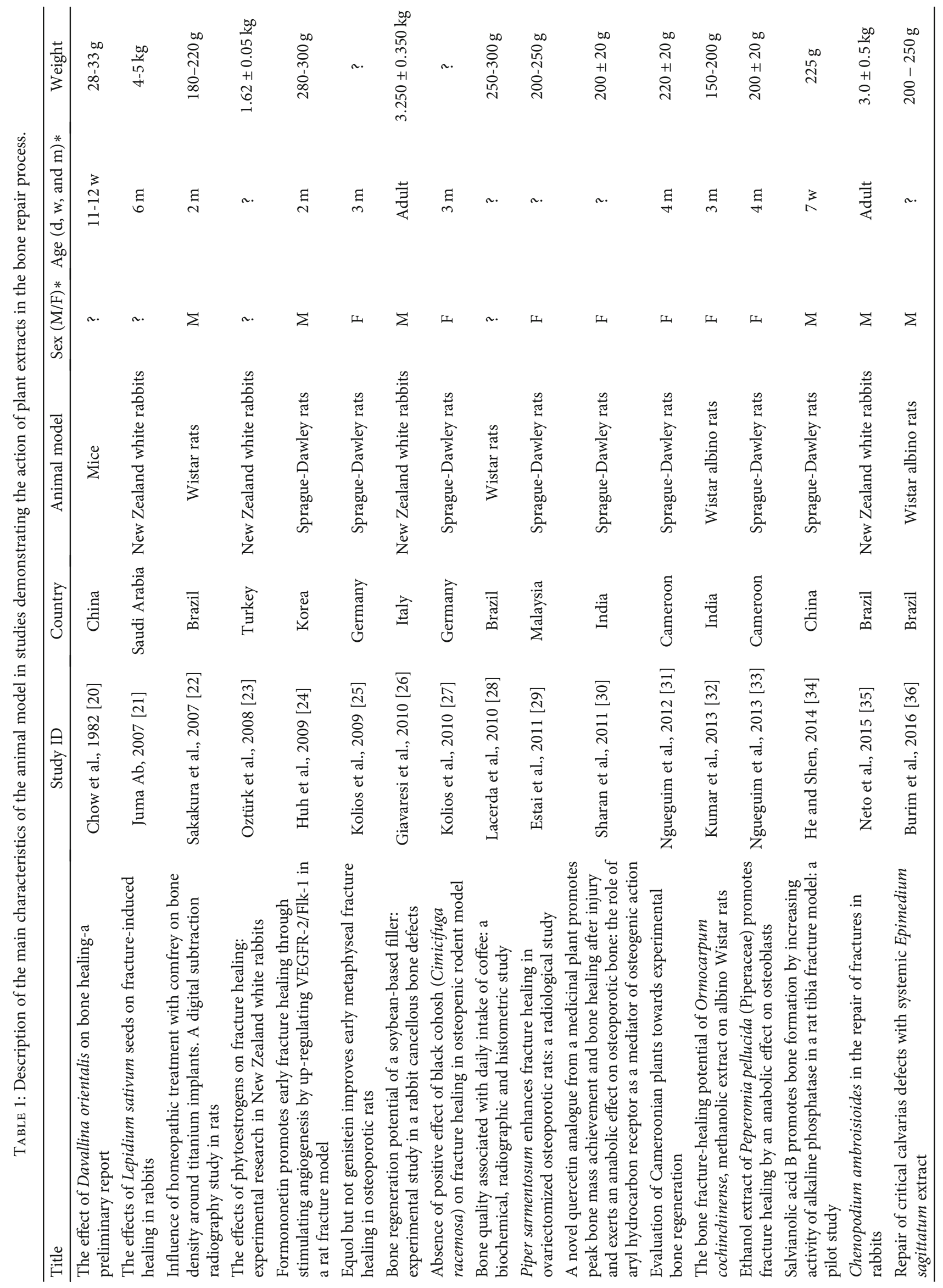




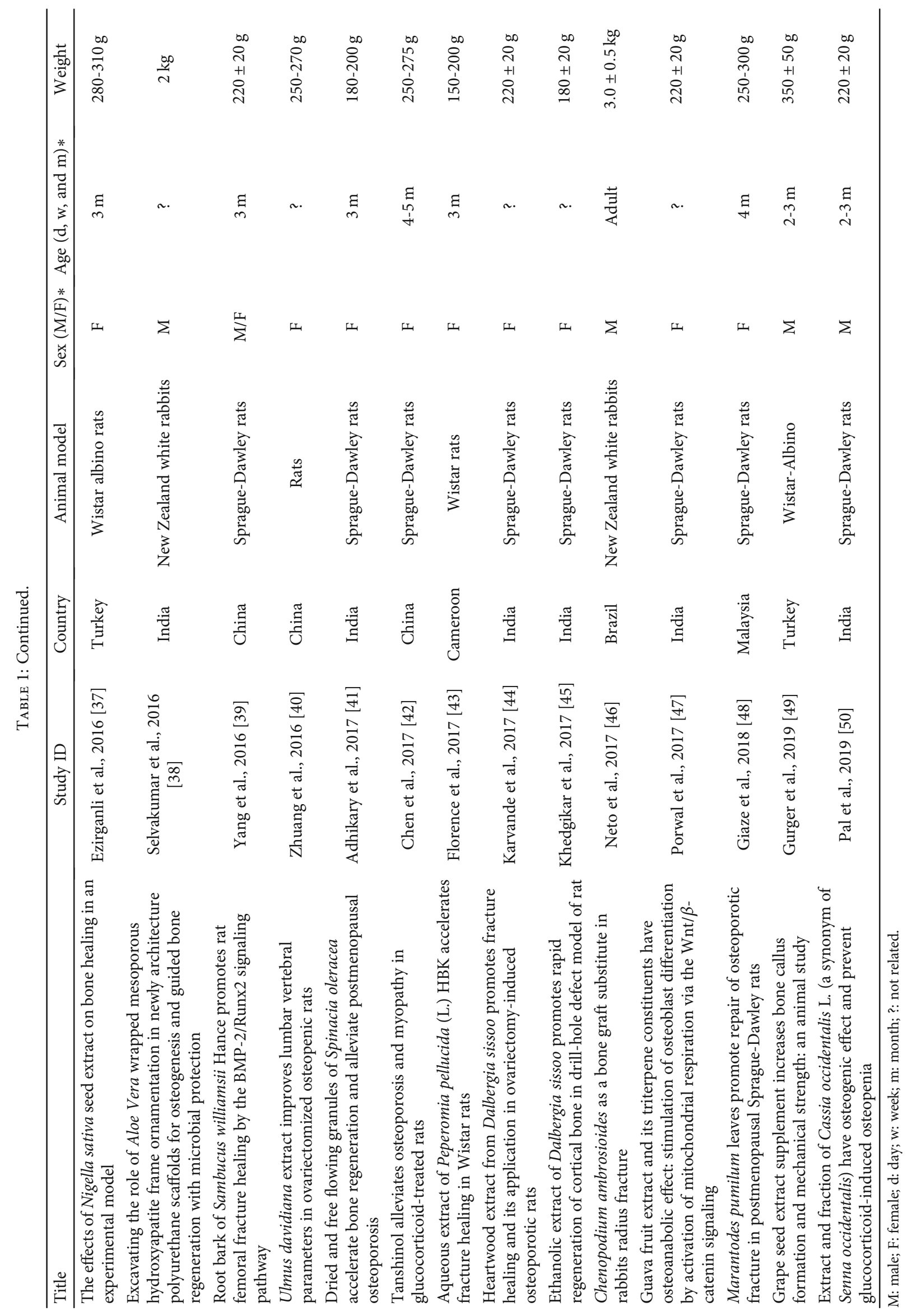


and 6 months for rabbits, and 32.26\% $(n=10)$ of the studies did not report this information. The weight of rats ranged from 150 to $350 \mathrm{~g}$, that of rabbits 1.62 to $5 \mathrm{~kg}$, and that of mice 28 to $33 \mathrm{~g}$, and $6.45 \%(n=2)$ of the studies did not report this data.

The most used treatments in the control groups were saline solution $(19.35 \%, n=6)$, followed by acacia $\mathrm{gum}$ in aqueous medium $(16.13 \%, n=5)$, and $9.68 \%(n=3)$ reported no treatment. Regarding the treatment time, there was great variation from 10 days $(6.45 \%, n=2)$ to 24 weeks $(3.22 \%, n=1)$. Eight studies $(25.81 \%)$ reported that they had induced osteoporosis in the animals and the method used was ovariectomy $(16.13 \%, n=5)$ or GlucocorticoidInduced Osteoporosis Program (GIOP) (3.22\%, $n=1)$. The most evaluated bone was the femur $(54.84 \%, n=17)$ followed by the tibia $(25.81 \%, n=8)$. The methods used to perform the induction of bone defects were described in $90.32 \% \quad(n=28)$ of the studies, and $45.16 \% \quad(n=14)$ were performed by insertion of a drill bit. A lesion of $0.8 \mathrm{~mm}$ in diameter was created in $29.03 \%(n=9)$ of the studies, and $38.70 \%(n=12)$ of the studies did not report this information. Regarding the anesthetic procedure, $51.61 \%(n=16)$ of the studies used ketamine and xylazine, 9.68\% $(n=3)$ used chloral hydrate, and 29.03\% $(n=9)$ did not use anesthesia. Most of the studies $(70.97 \%, n=22)$ did not use medicinal drugs postoperatively. More than half of the studies $(51.61 \%, n=16)$ did not report the euthanasia procedure of the animals, and $9.68 \%(n=3)$ used decapitation under anesthesia. The data cited above can be analyzed in Table 2 .

3.3. Treatment Characteristics. From the 31 studies, $83.87 \%$ $(n=26)$ reported the scientific name of the plant and $16.13 \%(n=5)$ cited only the popular name. The most used plant structures were the leaves $(25.81 \%, n=8)$, followed by the whole plant and roots (9.68\%, $n=3$ each), and $19.35 \%$ $(n=6)$ did not record this information. Many authors $(19.35 \%, n=6)$ did not report the solvent used to extract the components of the plant. Among the studies that presented such information, the most used solvents were ethanol $(38.70 \%, n=12)$ and a water/ethanol mixture $(12.90 \%, n=4)$. Most of the studies reported oral administration (ad libitum) $(51.61 \%, n=16)$; however, in $6.45 \%$ of the cases $(n=2)$, this information was not reported.

India was the most cited country $(9.68 \%, n=3)$, in relation to the geographical distribution of plant species, but many studies $(61.29 \%, n=19)$ did not record this information. In relation to the investigated plants, $48.39 \%(n=15)$ realized the phytochemical prospecting, $22.58 \%(n=7)$ of them quoted that the phytochemical components were already reported in the literature, and $29.03 \%(n=9)$ did not describe this information. The most common secondary metabolites were flavonoids, cited in $32.26 \%(n=10)$ of the studies. The anti-inflammatory activity of the extracts was reported in $51.61 \%(n=16)$ of the studies, indicating the wide use of plants for the treatments of various diseases (Table 3). The mechanisms of action promoted by plant extracts in the bone repair were neglected in all studies $(100 \%)$.
3.4. Main Parameters Analyzed to Evaluate the Extract Action in Bone Repair. The most analyzed parameters among the 31 papers found in this review were radiological analyses $(80.64 \%, n=25)$ [21-31, 33, 34, 36, 39, 41-50], followed by immunological and histopathological markers $(70.97 \%$, $n=22$ ) [23-28, 30-37, 39-44, 47, 48]. These analyses demonstrated mainly osteoblastic proliferation, angiogenesis, and increased formation of the bone matrix with fracture closure and bone callus formation. Only $25.81 \%(n=8)$ $[28,32,35,38,39,43,46,50]$ performed measurement of inflammatory markers, and the most cited parameters were $\mathrm{Ca}^{+2}$ content and serum alkaline phosphatase. Only $25.81 \%(n=8)[22,32,37,38,42,46,48,49]$ reported whether the fracture had complete, partial, or absent closure. Other analyses related to bone strength, tensile strength, and expression of inflammatory genes that stimulate bone formation and osteogenic differentiation were performed in $38.71 \%(n=12)$ of the studies $[20,23,24,28,33,36$, 40-42, 44, 45, 47] (Figure 2).

3.5. Bias Analysis. Detailed results of the bias analysis are depicted in Figure 3 and Table 4. An average of $77.63 \pm$ 10.97 ARRIVE items were met by the original included studies. In general, the studies published more recently have better met the methodological quality criteria analyzed. Primary and secondary objectives were clearly stated by $77.42 \% \quad(n=24)$ of the studies, while $80.64 \% \quad(n=25)$ reported ethics committee permission for performing the research. The number of animals per group was reported in $83.87 \%(n=26)$ of the studies, and only $32.26 \%(n=10)$ reported a blind controlled study. Most studies provided information about the treatment description (90.32\%, $n=28)$, the administered therapeutic dose $(93.55 \%, n=29)$, and treatment time $(96.2 \%, n=30)$. However, only $6.45 \%$ $(n=2)$ reported the period when the treatment was administered. All studies $(100 \%, n=31)$ reported the animal species, and $93.55 \%(n=29)$ described the animal strain. The sex and weight were reported in $87.09 \%(n=27)$ and $96.77 \%$ $(n=30)$ of the works, respectively, and $61.29 \%(n=19)$ of the studies provided information about the animals' age. No study reported the description of genetic modification status, and $45.16 \%(n=14)$ presented information regarding previous procedures performed on the animals. Among the articles, $29.03 \%(n=9)$ reported the housing of experimental animals (facility type, cage or housing type, material, and number of cage companions), and $48.39 \%(n=15)$ provided information about the experimental conditions (temperature, humidity, light cycles, feed, and water). Only $32.26 \%(n=10)$ of the studies performed assessments and interventions related to animal welfare. Regarding the sample size, $74.19 \%$ $(n=23)$ of the studies reported the total number of animals used and the number of animals in each experimental group, but only $3.22 \%(n=1)$ explained the reason for choosing such numbers. The details of how the animals were allocated to experimental groups (randomization or matching) were reported by $29.03 \%(n=9)$ of the studies, and no study described the order in which animals in different groups were treated and assessed. The experimental outcomes were clear in $90.32 \%(n=28)$ of the studies. Statistical analyses were 


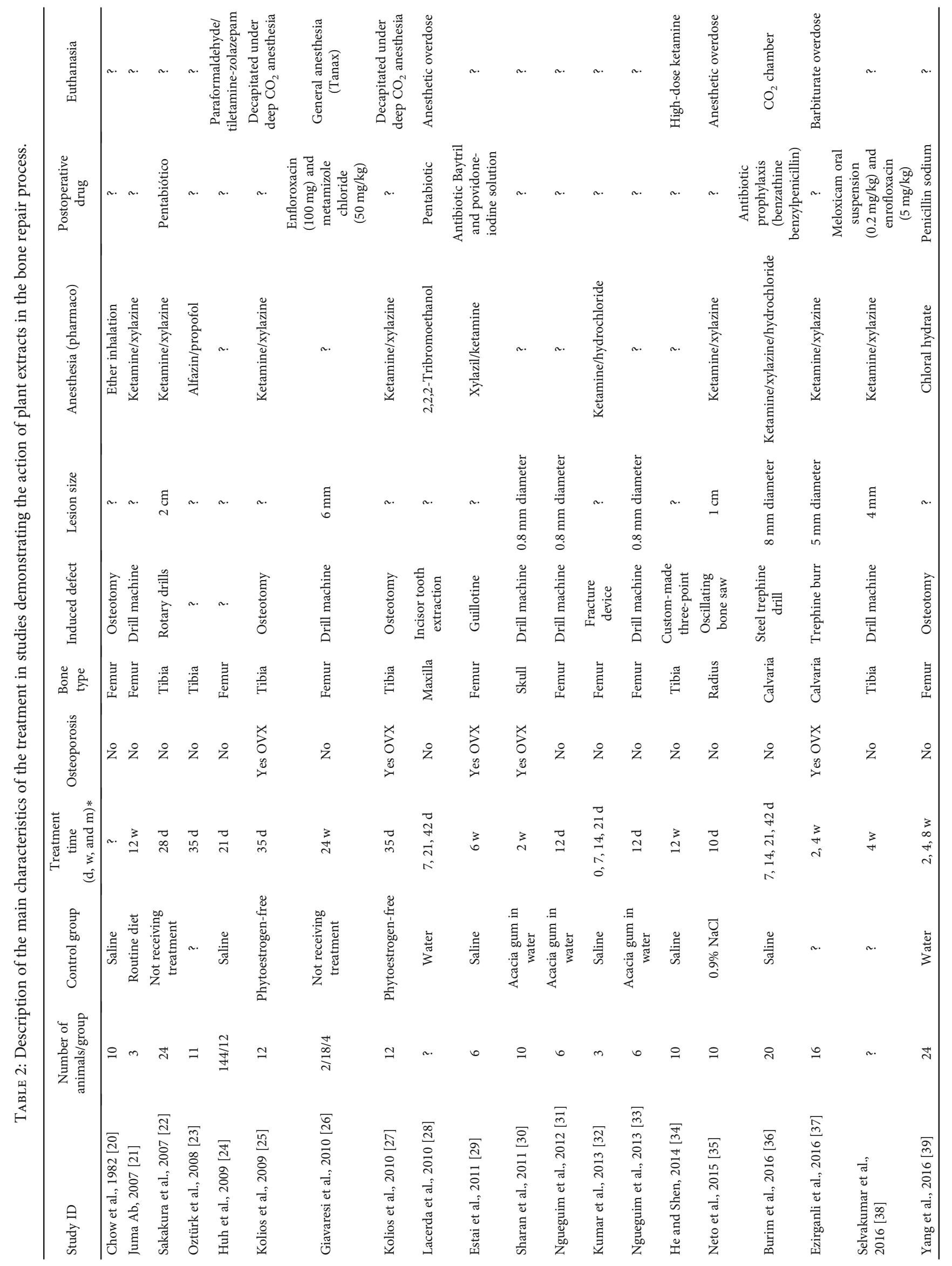




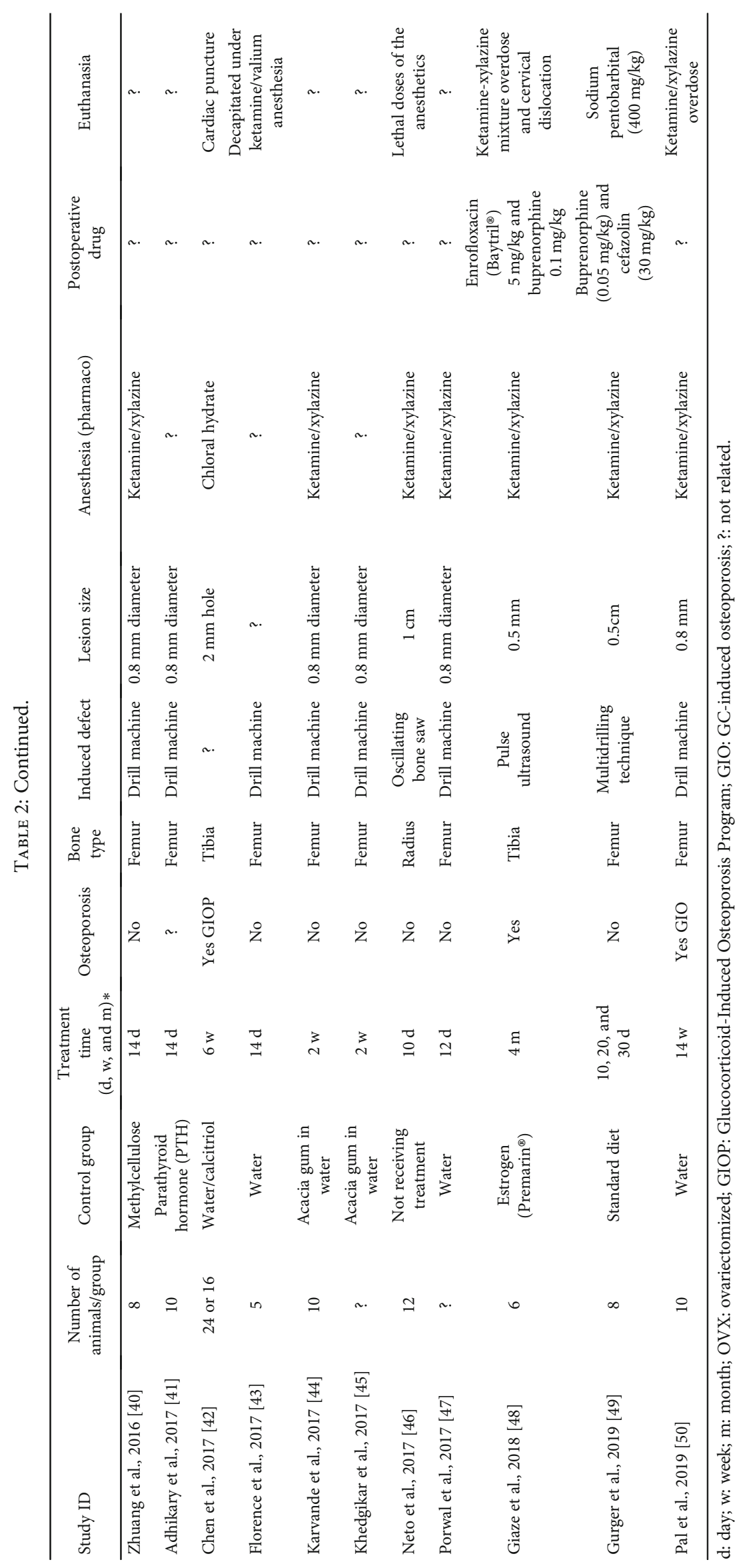




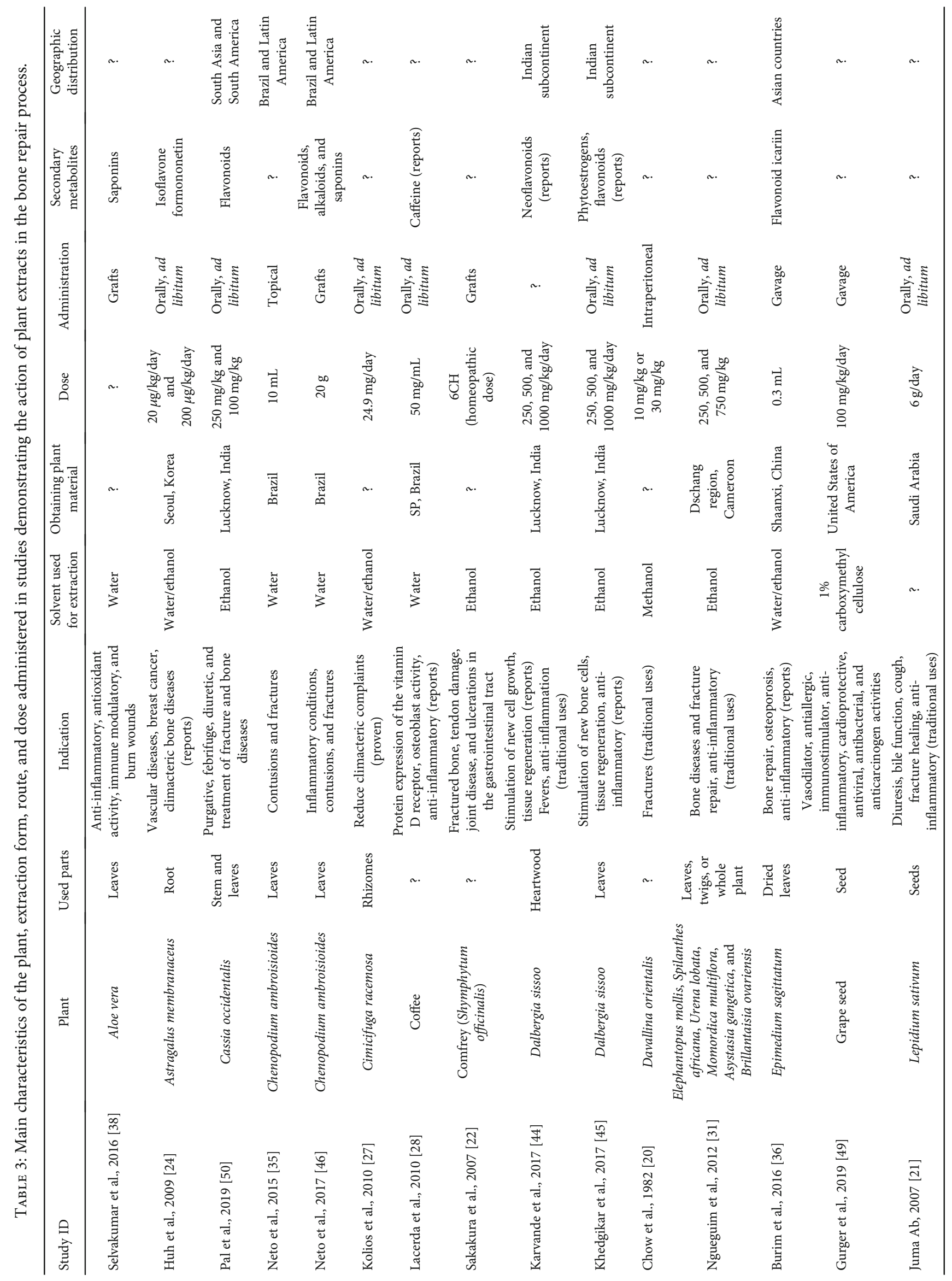




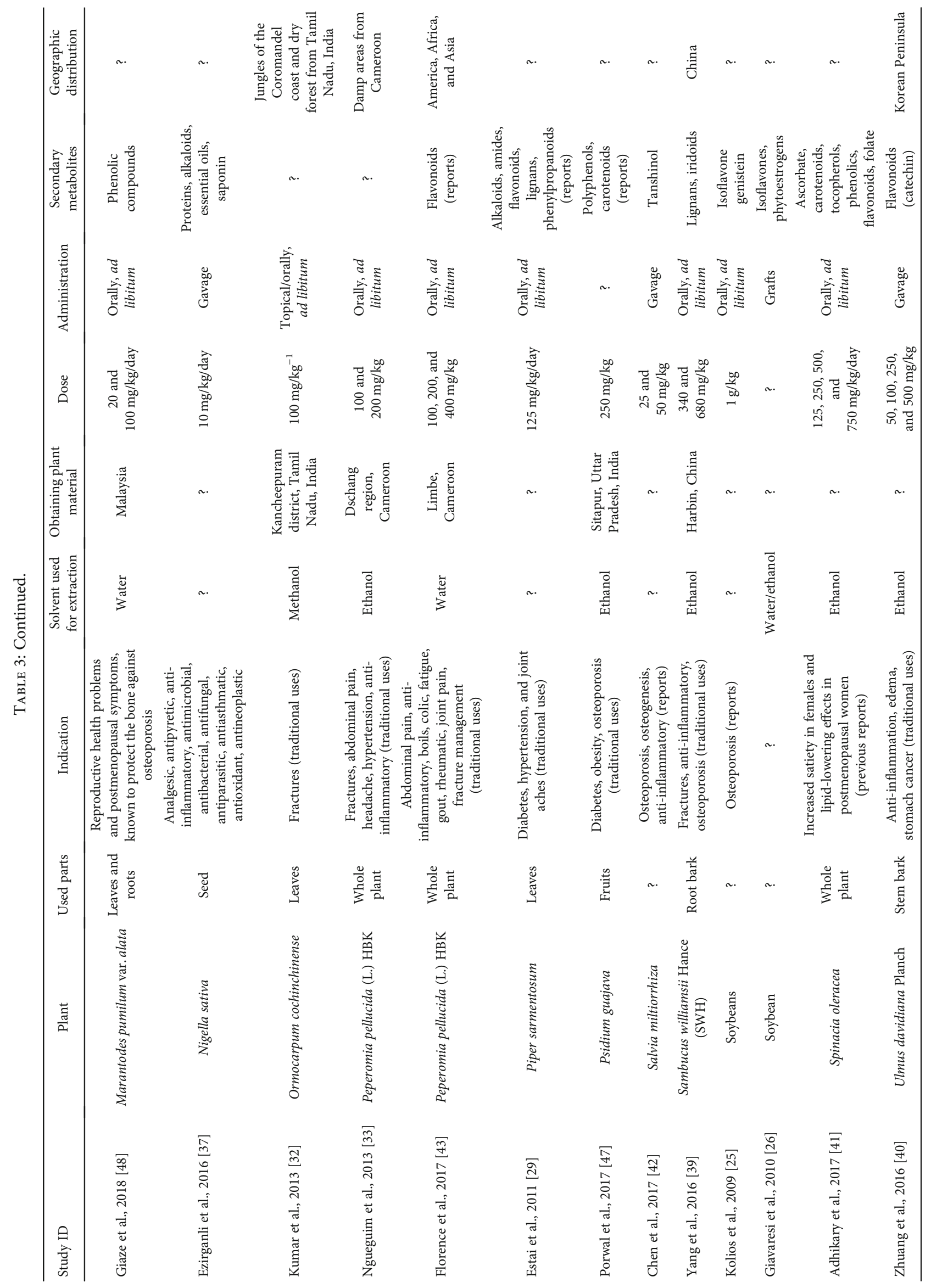




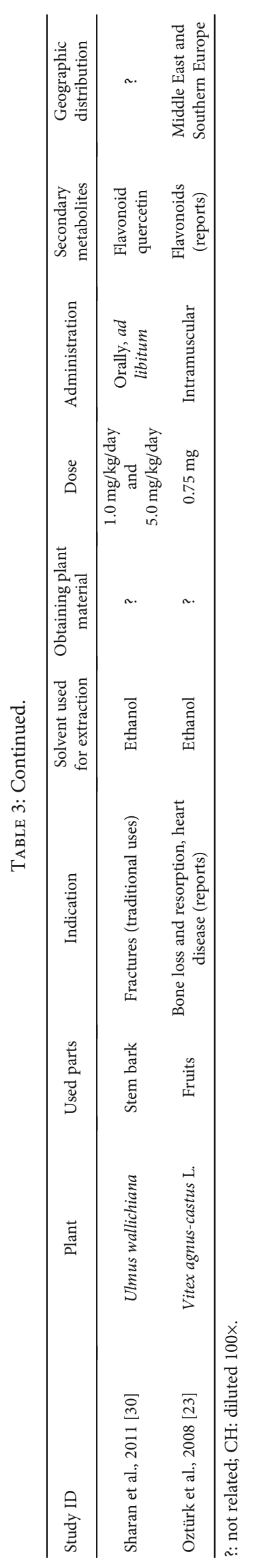




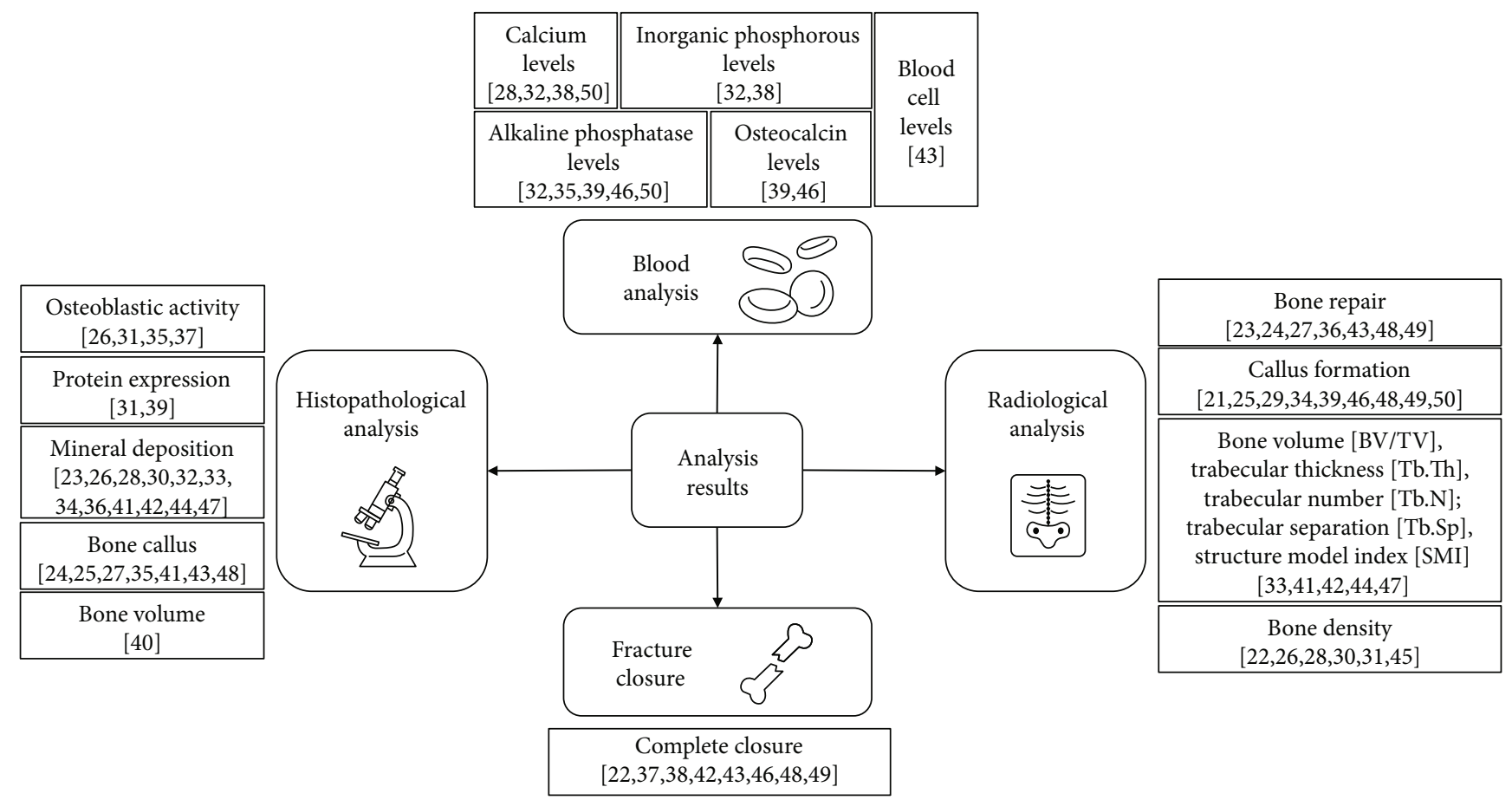

Figure 2: Main results of the studies demonstrating the action of plant extracts in the bone repair process.

performed by $90.32 \%(n=28)$ of the studies, $87.09 \%(n=27)$ of them specified the unit of analysis for each dataset, and $90.32 \%(n=28)$ specified the methods used to assess whether the data met the assumptions of the statistical approach. Information regarding mortality was described in $6.45 \%$ $(n=2)$ of the studies, and no study described modifications to the experimental protocols made to reduce adverse events. A coherent interpretation of the results and the direct relationship between objectives and hypothesis were described in all included studies $(100 \%, n=31)$, and $19.35 \%(n=6)$ commented on the limitations of the studies. Comments on the importance of applying the results to human biology were found in $45.16 \%(n=14)$ of the studies, and $45.16 \%(n=14)$ mentioned sources of funding and the role of the funder in the study.

\section{Discussion}

4.1. General Aspects. In this study, we conducted a systematic review to analyze the anti-inflammatory activity of plant extracts and their derivatives on bone repair in animal models. Despite the great heterogeneity of the studies, in general, the use of plant extracts was effective for treating bone lesions. We observed the release of markers and antiinflammatory mediators after treatment with plants, which accelerated the recovery process of bone repair. In addition, histopathological and radiological analyses demonstrating bone remodeling (new bone formation, bone callus, cell proliferation, and osteogenesis) were the main findings of this study, which suggests that some components of the extracts may favor the proliferation of certain cell types. This occurs probably due to the interactions of these cells with the components of the extracts. Taking into consideration that the biological activity of a natural product is generally due to the synergism between its constituents, which potentiates its therapeutic properties, the study of plants for the treatment of many different diseases has been increasing gradually [51-53]. We believe that the development of therapeutic strategies based on the use of plants is opening a new perspective and represents a promising therapy as an alternative to conventional medicine and synthetic products [54-56].

The use of natural products for the treatment of injuries is an old practice [57] and represents an important source of bioactive compounds that contribute directly to the development of new drugs [58]. Our findings showed that most of the studies were conducted in China and India, countries known for having a millenary practice in traditional medicine [59]. This interest is probably due to the extensive and diverse flora found in these countries and to the vast traditional ethnomedicinal knowledge that serves as a basis for the researches $[60,61]$. It is already known that the great ethnopharmacological potential of different phytotherapics favors and potentiates research in different health areas, thus directing the rational choice of medicinal plants $[62,63]$. In addition, it is noteworthy that in China $40 \%$ of all health care provision is based on medicinal plants $[64,65]$. However, the limiting factor found here was the language, which hinders access to information and reduces the dissemination of the data obtained to the scientific community [66].

As one of the objectives was to research experimental models closer to the human model, our study focused on in vivo experiments. Initially, all animal species were considered. However, after selection by inclusion criteria, only studies with rats, mice, and rabbits were admitted. It is noteworthy that there was a predominance of studies performed 


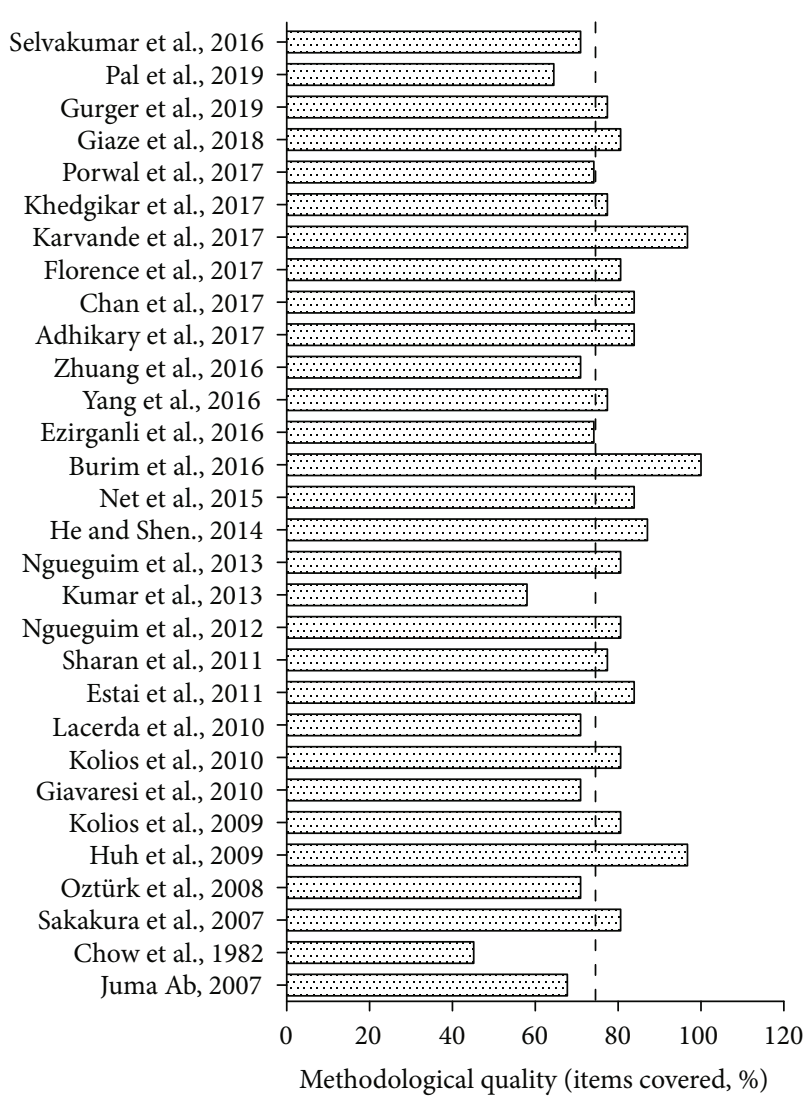

Figure 3: Analysis of methodological bias (reporting quality) for each study included in the review. Based on Animal Research: Reporting of In Vivo Experiments (ARRIVE) guidelines (http:// www.nc3rs.org.uk/arrive-guidelines). The dotted line indicated the mean quality score (\%). Detailed bias analysis stratified by domains and items evaluated is presented in Supplementary Material 1.

in murine models. Although these models do not allow the direct extrapolation of the results to human models [67], they can provide important insights into the biology and pathophysiology of the lesions and are indispensable for researchers [68]. The advantage of working with such animals is mainly due to reduced costs, as more animals can be housed in a limited space, and the shorter reproductive cycle. These characteristics allow, in a short time, a sufficient number of animals for large study groups, enabling a relevant statistical analysis [69].

4.2. Main Parameters Analyzed and Therapeutic Findings. The studies presented different methodologies, and this could be justified by the difference of objectives and parameters analyzed. However, important information such as sex, age, weight of the animals, and description of the methods for performing the induction of bone defect was neglected in some studies. The absence of this information compromises the comprehension of the studies, since biological and methodological variables directly affect the response to the treatments [70].

In addition to bone fracture, some studies have induced osteoporosis in animals, mainly to evaluate the action of phytotherapics as estrogen stimulants $[25,27,29,30,37,42]$.
Warriner et al. [71] published a systematic review investigating different works involving the association between bone fractures and osteoporosis and reported that the main fracture sites related to this disease were the vertebrae, femoral neck, radius, and ulna. In our review, we found that the most evaluated bone was the femur followed by the tibia, probably due to the greater resistance and size of these bones.

Two other parameters that varied widely were the size of the lesion or bone fracture and the treatment time, which can also compromise the reproduction of the work, as well as the comparison between the different groups treated with extracts. Image analysis, such as radiological findings and tomography, is fundamental for studies with fractures [72]. However, inflammatory and histopathological analyses play an important role in helping to interpret and confirm the cellular action of phytotherapeutic compounds in tissue repair [73]. The action of osteogenic cells on bone callus formation, cell organization, and the release of immunomarkers is a factor that can be confirmed by histology and immunohistochemistry [74-76], thus leading the experiment to a greater reliability of its results. The synthesis of proinflammatory mediators, in regions of spongy bone and compact bone, indicated in immunological and histopathological analyses, was higher in the phytotherapeutic treatment groups when compared to the control groups, demonstrating an efficiency of extracts in bone repair. This observation suggests that some of the components of the extract, or the synergism between them, may favor the synthesis of certain mediators and proliferation of cell types and, consequently, accelerate the synthesis of the bone matrix and the bone callus formation [77]. In this context, immunological, radiological, and histopathological analyses also confirm whether the fracture is strong and resistant and if it was totally, partially, or not closed. Similar results were found by Neto et al. [46] who evaluated the effect of a poultice prepared from the leaves of Chenopodium ambrosioides $L$. on bone repair in rabbits. Phytochemical analysis of the aqueous extract of this plant revealed the strong presence of saponins, flavonoids, tannins, and alkaloids, which may contribute to its effect on bone formation. These compounds are known for their antiinflammatory and antioxidant action, accelerating the proliferation of anti-inflammatory proteins and enzymes such as catalase and superoxide dismutase that are responsible for protection during bone repair [46].

The use of phytotherapics has been increasing considerably in the last years, indicating that phytotherapy currently represents an effective way to treat the most varied tissue dysfunctions $[78,79]$. This curative effect is probably related to the extensive source of bioactive compounds that are found in extracts obtained from natural products $[80,81]$. However, the positive effects may vary according to the species of the plant and its used part. It is common to find studies that demonstrate, through different chromatographic analyses, different concentrations of flavonoids, tannins, and triterpenes in the bark and leaves of the same plant species [82-84], and that the protective effect of an extract should consider the part of the plant, possibly associated with its antioxidant effect [85]. In this review, we observed that approximately a quarter of the studies do not provide 


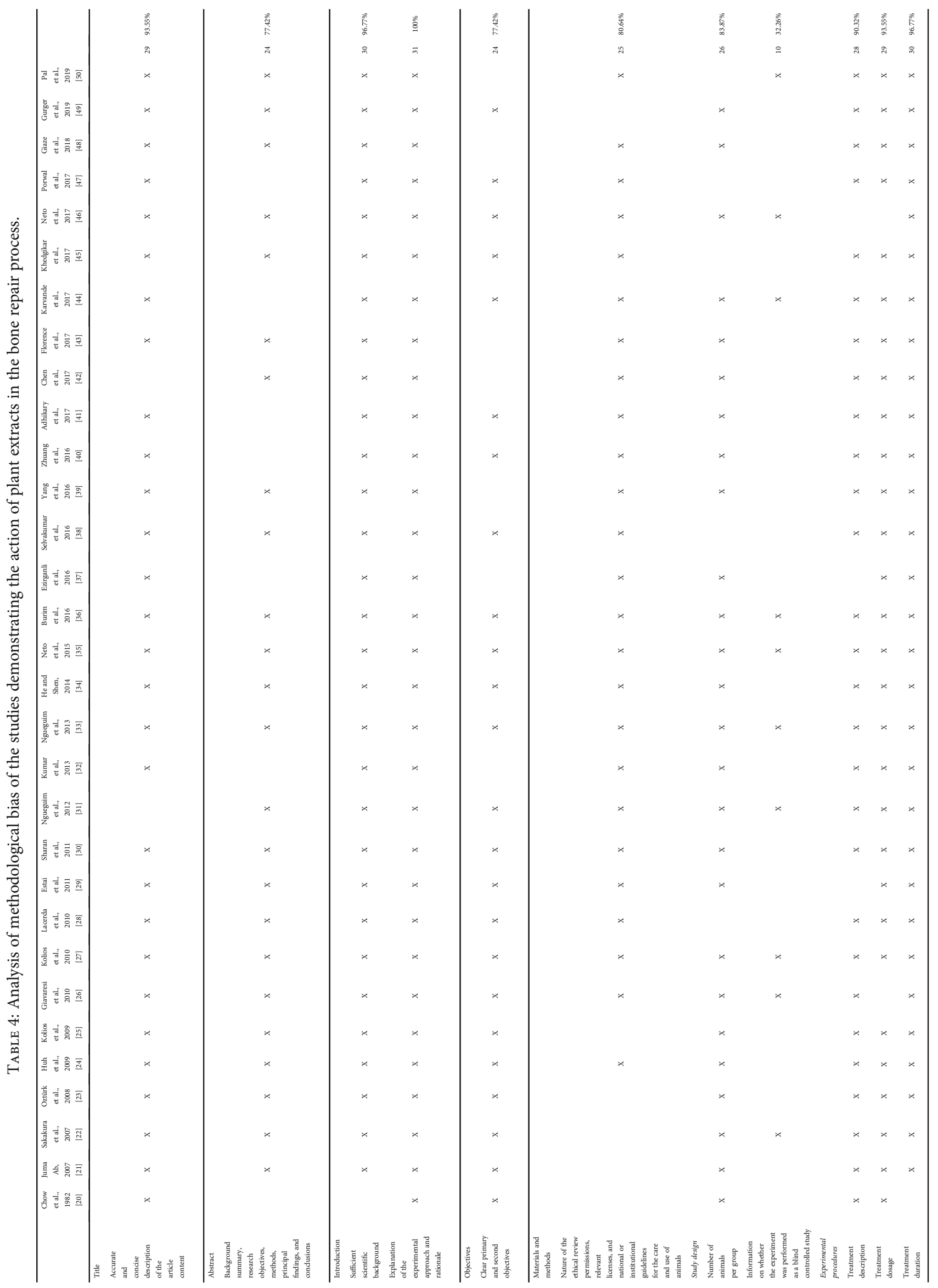




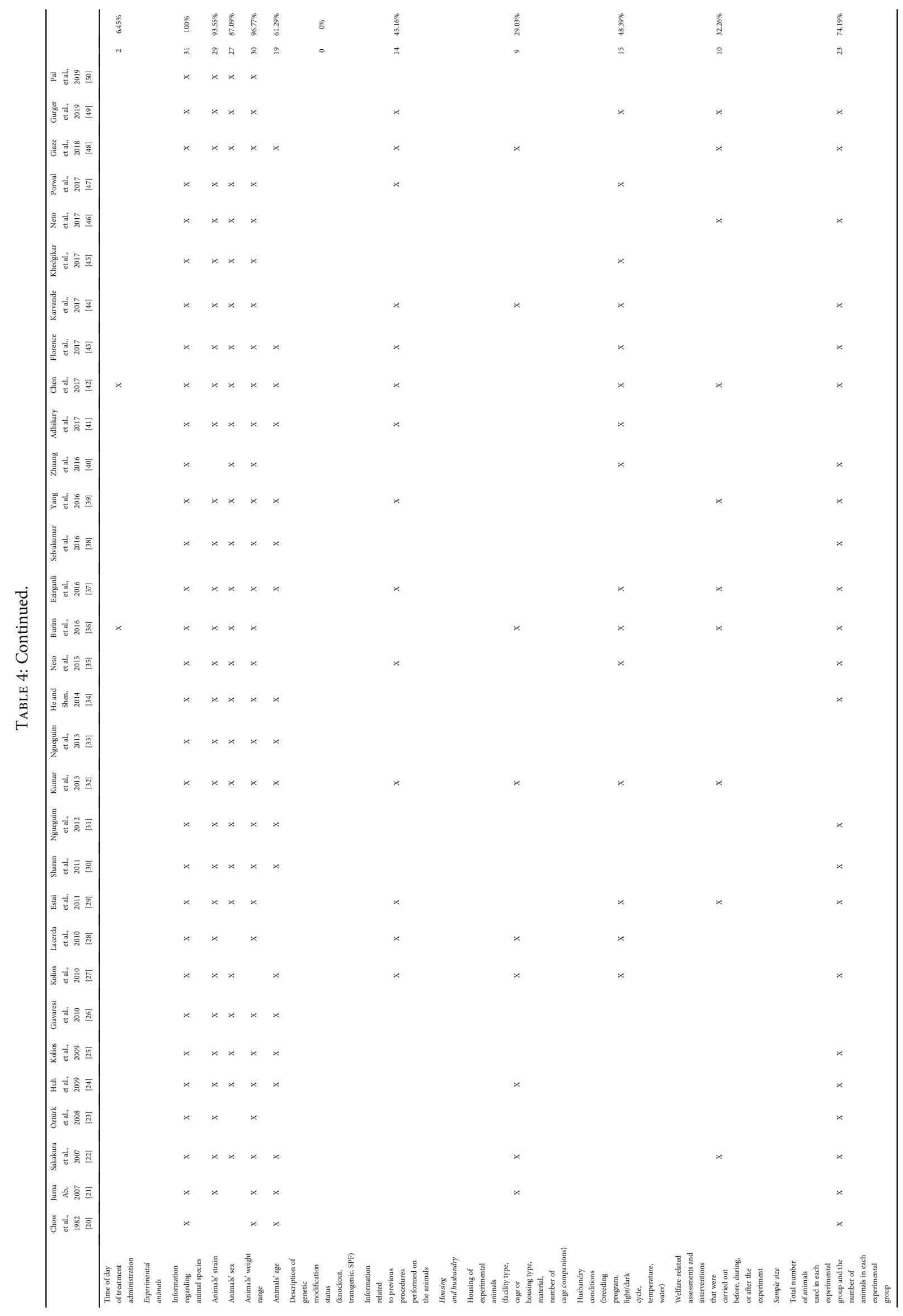




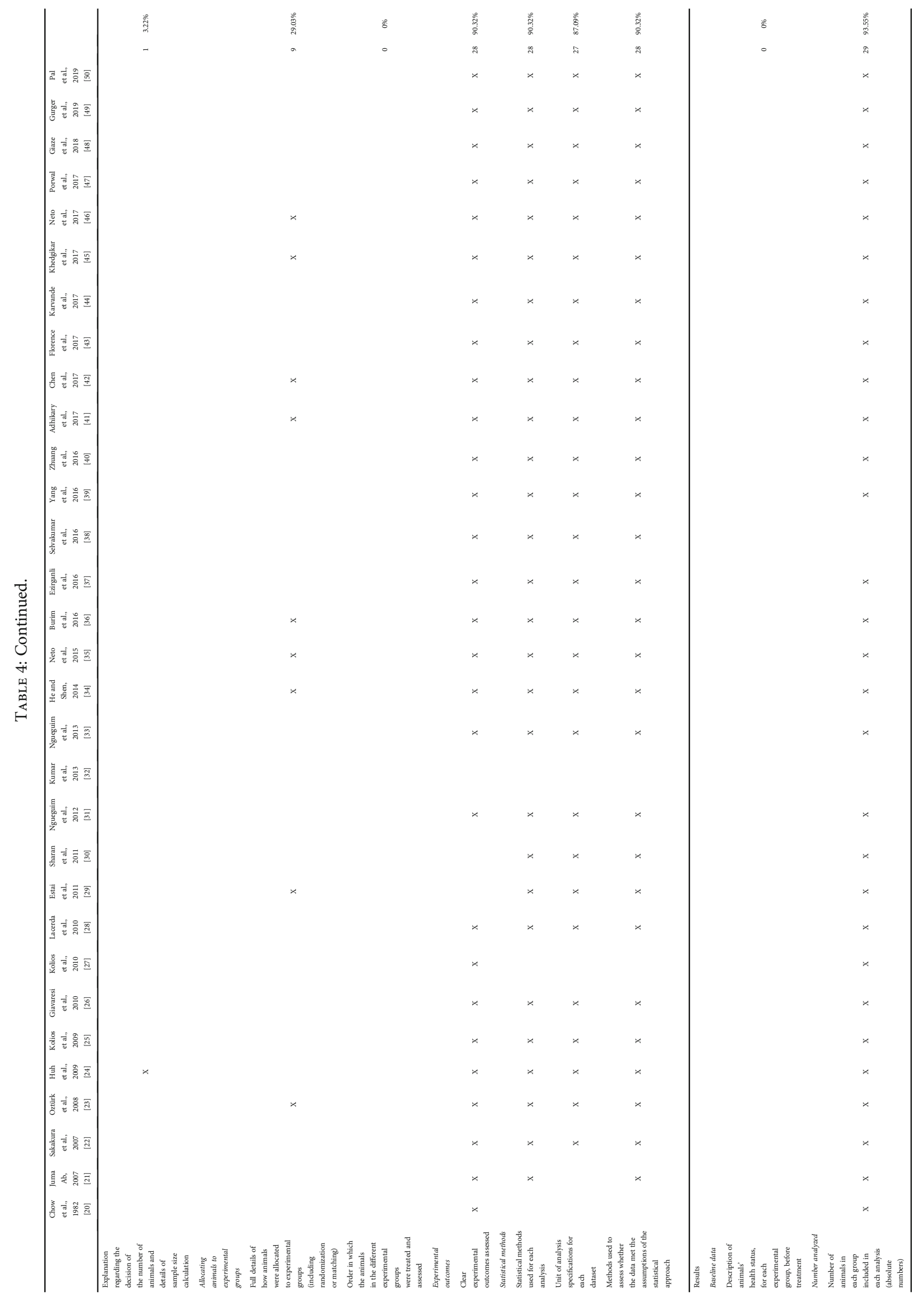




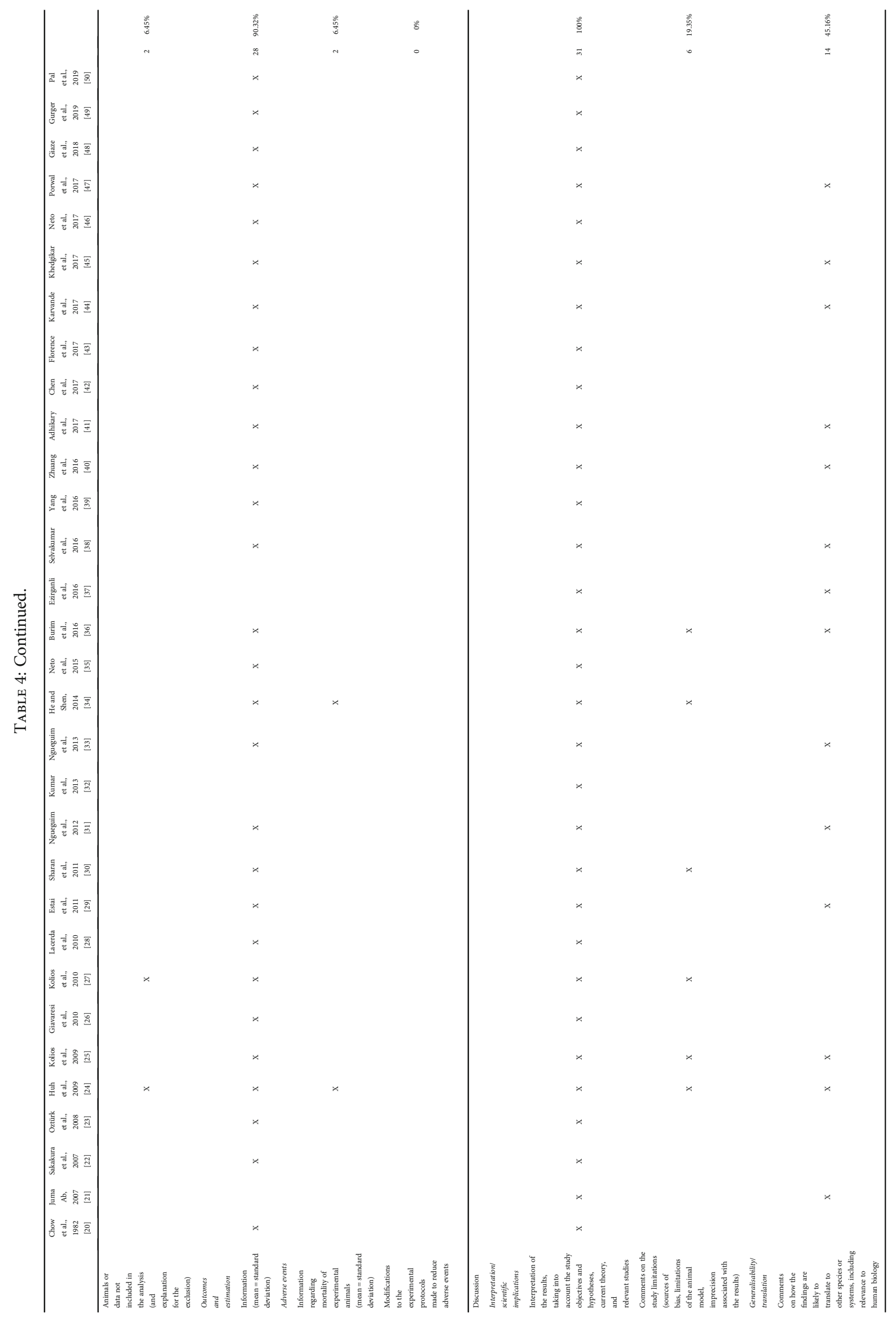




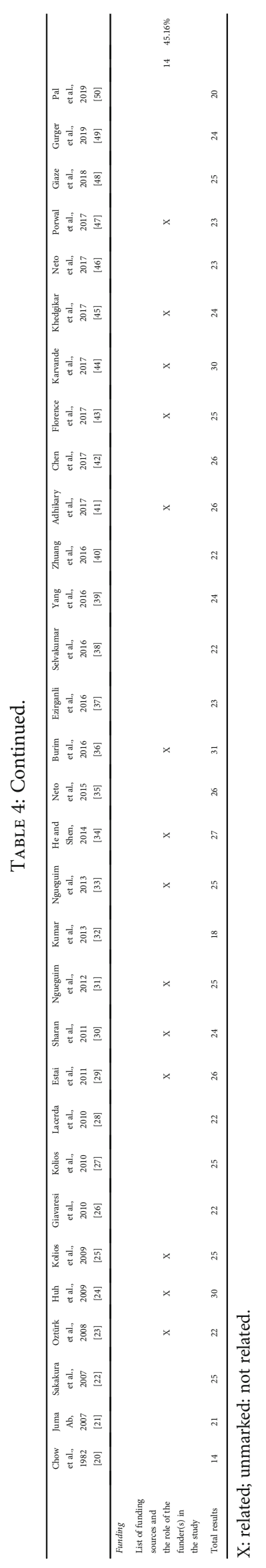


the scientific name of the species or the part of the plant used, which reduces the accuracy and reproducibility of these studies. The diversity of the compounds directly interferes with their performance in the organism, and their metabolites differ according to the parts of the plant, as well as the region and climate where they were collected [86]. As for the secondary metabolites found in the phytochemical description of the studies, we observed that $32.26 \%$ were flavonoids, indicating the positive action of this compound on the bone repair. The role of flavonoids in skin repair is already known, but recent studies have demonstrated the action of this compound also in bone repair $[23,29,30,36,40,41,43,45]$. Another important fact to be informed in works with phytotherapics is the knowledge about the extraction techniques as well as the solvents used, since they can determine the isolation of a biologically active compound, directing the research [87]. This bias was found frequently in our study, since $19.35 \%$ of the studies did not report the solvent used for extraction which makes it difficult to obtain the extract again.

For the analysis of the work quality, we used an approach based on the ARRIVE guide, describing minimum information that can compromise the quality of the writing as well as the reproduction of the study [19]. Aspects related to the organization and writing of the evaluated articles showed that more than half of the studies presented an introduction with relevant scientific basis, as well as clearly written objectives. Through the bias analysis, flaws were detected in the reporting of the methodological procedures of the experiments, and it was found that many papers neglected information about the Ethics Committee approval, double-blind studies, and experimental conditions, such as light cycles and randomization. These results point out the need to improve experimental designs and current guidelines in reporting animal experiments as means to ensure an adequate level of scientific evidence [88].

4.3. Limitations of the Study. A great contribution of this work is based on the global estimation of the use of plant extracts for the treatment of bone lesions. However, the results presented here should be interpreted with caution, since it can be argued that the selection process of the studies may be biased due to different factors, such as the initial exclusion based only on the reading of the titles and abstracts or the inclusion of more than one study of the same group of researchers. However, the work selection process carried out in our review was widely based on recommended and accepted practices for performing systematic reviews [17, 89].

Another relevant issue highlighted in our work is related to the bias of the publication. After this analysis, we realized that aspects related to the organization of the experiments were neglected, including lack of randomization. These factors highlight the need to enhance experimental designs and current guidelines in reporting animal experiments as means to ensure an adequate level of scientific evidence. Although most studies indicate possible effects such as osteoblastic proliferation, angiogenesis, and increased formation of the bone matrix with fracture closure and bone callus formation, the mechanisms of action of extracts on bone tissue are unclear. In addition, the lack of phytochemical characterization of most plant extracts makes it impossible to identify the compounds responsible for the positive effect.

Finally, it was observed that the methodologies used and the evaluation parameters are extremely heterogeneous, with different measures being reported in all the studies, such as analysis of the size of the lesion or fracture, as well as histopathological analyses. Despite the improvement in the methodological quality of individual studies from 2009, much still needs to be done to allow the reproducibility of the studies. Interestingly, most papers did not report whether the results of their studies could be translated into other species and systems, including some relevance to human biology [90]. Considering the experimental model used in most studies and the social relevance of bone lesions for the world population, the translation of the results and their applicability on the treatment of human diseases are fundamental to allow the continuity of studies with medicinal plants, once the goal is to develop a drug that improves the human quality of life.

\section{Conclusion}

The results of this study demonstrated that the use of plant extracts stimulates bone repair, increasing osteogenesis, the rate of calcification, and the formation and mineralization of bone callus, accelerating the process of new bone formation on the fracture region. Possibly, these effects are related to anti-inflammatory and antioxidant power of these extracts. However, the methodological flaws found in some studies make it difficult to understand and use data in studies for the human condition. Therefore, more complete methodological descriptions are needed to better compare the studies and to allow the reproducibility of future trials.

\section{Conflicts of Interest}

The authors declare that there is no conflict of interest regarding the publication of this paper.

\section{Acknowledgments}

Thanks are due to the Coordenação de Aperfeiçoamento de Pessoal de Nível Superior (CAPES, finance code 001), Conselho Nacional de Desenvolvimento Científico e Tecnológico (CNPq, processes 305093/2017-7, 303972/2017-3, and MCTIC 408503/2018-1), and Fundação de Amparo à Pesquisa do Estado de Minas Gerais (FAPEMIG-PPM-00687-17).

\section{Supplementary Materials}

Table S1: full search strategy in PubMed and Scopus, including search terms and filters. (Supplementary Materials)

\section{References}

[1] F. Loi, L. A. Córdova, J. Pajarinen, T. H. Lin, Z. Yao, and S. B. Goodman, "Inflammation, fracture and bone repair," Bone, vol. 86, pp. 119-130, 2016.

[2] H. E. Rosberg and L. B. Dahlin, "An increasing number of hand injuries in an elderly population - a retrospective study 
over a 30-year period," BMC Geriatrics, vol. 18, no. 1, p. 68, 2018.

[3] K. N. Tu, J. D. Lie, C. K. V. Wan et al., "Osteoporosis: a review of treatment options," Pharmacy and Therapeutics, vol. 43, no. 2, pp. 92-104, 2018.

[4] B. Langdahl, S. Ferrari, and D. W. Dempster, "Bone modeling and remodeling: potential as therapeutic targets for the treatment of osteoporosis," Therapeutic Advances in Musculoskeletal Disease, vol. 8, no. 6, pp. 225-235, 2016.

[5] S. Levy, J. M. Feduska, A. Sawant, S. R. Gilbert, J. A. Hensel, and S. Ponnazhagan, "Immature myeloid cells are critical for enhancing bone fracture healing through angiogenic cascade," Bone, vol. 93, pp. 113-124, 2016.

[6] A. Oryan, S. Monazzah, and A. Bigham-Sadegh, "Bone injury and fracture healing biology," Biomedical and Environmental Sciences, vol. 28, no. 1, pp. 57-71, 2015.

[7] K. D. Hankenson, K. Gagne, and M. Shaughnessy, "Extracellular signaling molecules to promote fracture healing and bone regeneration," Advanced Drug Delivery Reviews, vol. 94, pp. 3-12, 2015.

[8] E. Gibon, L. Lu, and S. B. Goodman, "Aging, inflammation, stem cells, and bone healing," Stem Cell Research \& Therapy, vol. 7, no. 1, 2016.

[9] Q. Gu, H. Yang, and Q. Shi, "Macrophages and bone inflammation," Journal of Orthopaedic Translation, vol. 10, pp. 86-93, 2017.

[10] C. Patel, R. M. Ayaz, and P. Parikh, "Studies on the osteoprotective and antidiabetic activities of Moringa Oleifera plant extract," IOSR Journal of Pharmacy and Biological Sciences, vol. 5, pp. 19-22, 2015.

[11] D. M. Kasote, S. D. Jagtap, D. Thapa, M. S. Khyade, and W. R. Russell, "Herbal remedies for urinary stones used in India and China: a review," Journal of Ethnopharmacology, vol. 203, pp. 55-68, 2017.

[12] B. Beyene, B. Beyene, and H. Deribe, "Review on application and management of medicinal plants for the livelihood of the local community," Journal of Resources Development and Management, vol. 22, pp. 33-39, 2016.

[13] P. Arulselvan, M. T. Fard, W. S. Tan et al., "Role of Antioxidants and Natural Products in Inflammation," Oxidative Medicine and Cellular Longevity, vol. 2016, pp. 1-15, 2016.

[14] W. Xue, J. Yu, and W. Chen, "Plants and their bioactive constituents in mesenchymal stem cell-based periodontal regeneration: a novel prospective," BioMed Research International, vol. 2018, Article ID 7571363, 15 pages, 2018.

[15] L. A. Nash and W. E. Ward, "Tea and bone health: findings from human studies, potential mechanisms, and identification of knowledge gaps," Critical Reviews in Food Science and Nutrition, vol. 57, no. 8, pp. 1603-1617, 2017.

[16] V. L. Udalamaththa, C. D. Jayasinghe, and P. V. Udagama, "Potential role of herbal remedies in stem cell therapy: proliferation and differentiation of human mesenchymal stromal cells," Stem Cell Research \& Therapy, vol. 7, no. 1, pp. 110-118, 2016.

[17] D. Moher, A. Liberati, J. Tetzlaff, D. G. Altman, and The PRISMA Group, "Preferred Reporting Items for Systematic and Meta-Analyses: the PRISMA statement," PLoS Medicine, vol. 6, no. 7, p. e1000097, 2009.

[18] C. R. Hooijmans, A. Tillema, M. Leenaars, and M. RitskesHoitinga, "Enhancing search efficiency by means of a search filter for finding all studies on animal experimentation in
PubMed," Laboratory Animals, vol. 44, no. 3, pp. 170-175, 2010.

[19] C. Kilkenny, W. J. Browne, I. C. Cuthill, M. Emerson, and D. G. Altman, "Improving bioscience research reporting: the ARRIVE guidelines for reporting animal research," PLoS Biology, vol. 8, no. 6, p. e1000412, 2010.

[20] S. P. Chow, H. W. Yeung, L. K. Law, T. M. Chan, and C. Lau, "The effect of Davallina Orientalis on bone healing - a preliminary report," The American Journal of Chinese Medicine, vol. 10, no. 01n04, pp. 101-106, 1982.

[21] A. B. H. bin Abdullah Juma, "The effects of Lepidium sativum seeds on fracture-induced healing in rabbits," Medscape General Medicine, vol. 9, 2007.

[22] C. E. Sakakura, R. S. Neto, M. Bellucci, A. Wenzel, G. Scaf, and E. Marcantonio, "Influence of homeopathic treatment with comfrey on bone density around titanium implants. A digital subtraction radiography study in rats," Clinical Oral Implants Research, vol. 19, no. 6, pp. 624-628, 2008.

[23] A. Oztürk, A. A. Ilman, H. Sağlam et al., "The effects of phytoestrogens on fracture healing: experimental research in New Zealand white rabbits," Ulus Travma Acil Cerrahi Derg, vol. 14, no. 1, pp. 21-27, 2008.

[24] J. E. Huh, N. H. Kwon, Y. H. Baek et al., "Formononetin promotes early fracture healing through stimulating angiogenesis by up-regulating VEGFR-2/Flk-1 in a rat fracture model," International Immunopharmacology, vol. 9, no. 12, pp. 13571365, 2009.

[25] L. Kolios, S. Sehmisch, F. Daub et al., "Equol but not genistein improves early metaphyseal fracture healing in osteoporotic rats," Planta Medica, vol. 75, no. 05, pp. 459-465, 2009.

[26] G. Giavaresi, M. Fini, J. Salvage et al., "Bone regeneration potential of a soybean-based filler: experimental study in a rabbit cancellous bone defects," Journal of Materials Science: Materials in Medicine, vol. 21, no. 2, pp. 615-626, 2010.

[27] L. Kolios, J. Schumann, S. Sehmisch et al., "Effects of black cohosh (Cimicifuga racemosa) and estrogen on metaphyseal fracture healing in the early stage of osteoporosis in ovariectomized rats," Planta Medica, vol. 76, no. 09, pp. 850-857, 2010.

[28] S. A. Lacerda, R. I. Matuoka, R. M. Macedo, S. O. Petenusci, A. A. Campos, and L. G. Brentegani, "Bone quality associated with daily intake of coffee: a biochemical, radiographic and histometric study," Brazilian Dental Journal, vol. 21, no. 3, pp. 199-204, 2010.

[29] M. A. Estai, F. H. Suhaimi, S. Das et al., "Piper sarmentosum enhances fracture healing in ovariectomized osteoporotic rats: a radiological study," Clinics, vol. 66, no. 5, pp. 865-872, 2011.

[30] K. Sharan, J. S. Mishra, G. Swarnkar et al., "A novel quercetin analogue from a medicinal plant promotes peak bone mass achievement and bone healing after injury and exerts an anabolic effect on osteoporotic bone: the role of aryl hydrocarbon receptor as a mediator of osteogenic action," Journal of Bone and Mineral Research, vol. 26, no. 9, pp. 2096-2111, 2011.

[31] F. T. Ngueguim, M. P. Khan, J. H. Donfack et al., "Evaluation of Cameroonian plants towards experimental bone regeneration," Journal of Ethnopharmacology, vol. 141, no. 1, pp. 331-337, 2012.

[32] M. D. Kumar, K. M. M. John, and S. Karthik, "The bone fracture-healing potential of Ormocarpum cochinchinense, methanolic extract on albino Wistar rats," Journal of Herbs, Spices \& Medicinal Plants, vol. 19, no. 1, pp. 1-10, 2013. 
[33] F. T. Ngueguim, M. P. Khan, J. H. Donfack et al., "Ethanol extract of Peperomia pellucida (Piperaceae) promotes fracture healing by an anabolic effect on osteoblasts," Journal of Ethnopharmacology, vol. 148, no. 1, pp. 62-68, 2013.

[34] X. He and Q. Shen, "Salvianolic acid B promotes bone formation by increasing activity of alkaline phosphatase in a rat tibia fracture model: a pilot study," BMC Complementary and Alternative Medicine, vol. 14, no. 1, 2014.

[35] V. F. Pinheiro Neto, R. M. Ribeiro, C. S. Morais et al., "Chenopodium ambroisioides in the repair of fractures in rabbits," International Journal of Pharmacology, vol. 11, pp. 732-737, 2015.

[36] R. A. Burim, D. I. Sendyk, L. S. Hernandes, D. F. M. de Souza, L. Correa, and M. C. Z. Deboni, "Repair of critical calvarias defects with systemic Epimedium sagittatum extract," Journal of Craniofacial Surgery, vol. 27, no. 3, pp. 799-804, 2016.

[37] S. Ezirganli, H. O. Kazancioglu, H. Ozdemir, D. S. Inan, and M. Tek, "The effects of Nigella sativa seed extract on bone healing in an experimental model," Journal of Craniofacial Surgery, vol. 27, no. 7, pp. 1905-1909, 2016.

[38] M. Selvakumar, H. S. Pawar, N. K. Francis, B. Das, S. Dhara, and S. Chattopadhyay, "Excavating the role of Aloe Vera wrapped mesoporous hydroxyapatite frame ornamentation in newly architectured polyurethane scaffolds for osteogenesis and guided bone regeneration with microbial protection," ACS Applied Materials \& Interfaces, vol. 8, no. 9, pp. 5941-5960, 2016.

[39] B. Yang, X. Lin, J. Tan, X. She, Y. Liu, and H. Kuang, "Root bark of Sambucus Williamsii Hance promotes rat femoral fracture healing by the BMP-2/Runx2 signaling pathway," Journal of Ethnopharmacology, vol. 191, pp. 107-114, 2016.

[40] X. Zhuang, C. Fu, W. Liu et al., "Ulmus davidiana extract improves lumbar vertebral parameters in ovariectomized osteopenic rats," American Journal of Translational Research, vol. 8, no. 2, pp. 298-313, 2016.

[41] S. Adhikary, D. Choudhary, N. Ahmad et al., "Dried and free flowing granules of Spinacia oleracea accelerate bone regeneration and alleviate postmenopausal osteoporosis," Menopause, vol. 24, no. 6, pp. 686-698, 2017.

[42] G. Chen, X. Zhang, H. Lin, G. Huang, Y. Chen, and L. Cui, "Tanshinol alleviates osteoporosis and myopathy in glucocorticoid-treated rats," Planta Medica, vol. 83, no. 16, pp. 1264-1273, 2017.

[43] N. T. Florence, S. T. S. Huguette, D. J. Hubert et al., "Aqueous extract of Peperomia pellucida (L.) HBK accelerates fracture healing in Wistar rats," BMC Complementary and Alternative Medicine, vol. 17, no. 1, p. 188, 2017.

[44] A. Karvande, V. Khedgikar, P. Kushwaha et al., "Heartwood extract from Dalbergia sissoo promotes fracture healing and its application in ovariectomy-induced osteoporotic rats," Journal of Pharmacy and Pharmacology, vol. 69, no. 10, pp. 1381-1397, 2017.

[45] V. Khedgikar, P. Kushwaha, N. Ahmad et al., "Ethanolic extract of Dalbergia sissoo promotes rapid regeneration of cortical bone in drill-hole defect model of rat," Biomedicine \& Pharmacotherapy, vol. 86, pp. 16-22, 2017.

[46] V. F. Pinheiro Neto, R. M. Ribeiro, C. S. Morais et al., "Chenopodium ambrosioides as a bone graft substitute in rabbits radius fracture," BMC Complementary and Alternative Medicine, vol. 17, no. 1, p. 350, 2017.
[47] K. Porwal, S. Pal, K. Dev et al., "Guava fruit extract and its triterpene constituents have osteoanabolic effect: stimulation of osteoblast differentiation by activation of mitochondrial respiration via the Wnt/ $\beta$-catenin signaling," The Journal of Nutritional Biochemistry, vol. 44, pp. 22-34, 2017.

[48] T. R. Giaze, A. N. Shuid, I. N. Soelaiman et al., "Marantodes pumilum leaves promote repair of osteoporotic fracture in postmenopausal Sprague-Dawley rats," International Journal of Pharmacology, vol. 14, no. 7, pp. 973-980, 2018.

[49] M. Gurger, E. Yilmaz, S. Yilmaz et al., "Grape seed extract supplement increases bone callus formation and mechanical strength: an animal study," Journal of Orthopaedic Surgery and Research, vol. 14, no. 1, p. 206, 2019.

[50] S. Pal, P. Kumar, E. Ramakrishna et al., "Extract and fraction of Cassia occidentalis L. (a synonym of Senna occidentalis) have osteogenic effect and prevent glucocorticoid-induced osteopenia," Journal of Ethnopharmacology, vol. 235, pp. 8-18, 2019.

[51] N. K. Dubey, R. Kumar, and P. Tripathi, "Global promotion of herbal medicine: India's opportunity," Current Science, vol. 86, pp. 37-41, 2004.

[52] N. N. Azwanida, "A review on the extraction methods use in medicinal plants, principle, strength and limitation," Medicinal and Aromatic Plants, vol. 4, 2015.

[53] S. Perviz, H. Khan, and A. Pervaiz, "Plant alkaloids as an emerging therapeutic alternative for the treatment of depression," Frontiers in Pharmacology, vol. 7, 2016.

[54] G. Mishra, S. Srivastava, and B. P. Nagori, "Pharmacological and therapeutic activity of Cissus quadrangularis: an overview," International Journal of PharmTech Research, vol. 2, pp. 1298-1310, 2010.

[55] E. D. Staren and S. Omer, "Hormone replacement therapy in postmenopausal women," The American Journal of Surgery, vol. 188, no. 2, pp. 136-149, 2004.

[56] A. B. Abdel-Naim, A. A. Alghamdi, M. M. Algandaby et al., "Rutin isolated from Chrozophora tinctoria enhances bone cell proliferation and ossification markers," Oxidative Medicine and Cellular Longevity, vol. 2018, Article ID 5106469, 10 pages, 2018.

[57] N. E. Thomford, D. A. Senthebane, A. Rowe et al., "Natural products for drug discovery in the 21 st century: innovations for novel drug discovery," International Journal of Molecular Sciences, vol. 19, no. 6, p. 1578, 2018.

[58] V. Suvarna, M. Sarkar, P. Chaubey et al., "Bone health and natural products-an insight," Frontiers in Pharmacology, vol. 9, 2018.

[59] Z. Nooreen, V. K. Rai, and N. P. Yadav, "Phytopharmaceuticals: a new drug class regulated in India," Annals of Phytomedicine, vol. 7, pp. 27-37, 2018.

[60] A. J. T. Sangma and U. K. Sahoo, "Utilization pattern of medicinal plants by different tribes of garo hills of meghalaya, NorthEast India," American Journal of Ethnomedicine, vol. 4, 2017.

[61] G. Singh, A. K. Passsari, V. V. Leo et al., "Evaluation of phenolic content variability along with antioxidant, antimicrobial, and cytotoxic potential of selected traditional medicinal plants from India," Frontiers in Plant Science, vol. 7, 2016.

[62] L. Zhang, H. Zhuang, Y. Zhang et al., "Plants for health: an ethnobotanical 25-year repeat survey of traditional medicine sold in a major marketplace in North-west Yunnan, China," Journal of Ethnopharmacology, vol. 224, pp. 119-125, 2018.

[63] Y. Shi, A. M. Mon, Y. Fu et al., "The genus Ficus (Moraceae) used in diet: its plant diversity, distribution, traditional uses 
and ethnopharmacological importance," Journal of Ethnopharmacology, vol. 226, pp. 185-196, 2018.

[64] P. Shengji, A. C. Hamilton, Y. Lixin et al., "Conservation and development through medicinal plants: a case study from Ludian (Northwest Yunnan, China) and presentation of a general model," Biodiversity and Conservation, vol. 19, no. 9, pp. 2619-2636, 2010.

[65] L. Lao, L. Xu, and S. Xu, “Traditional chinese medicine," in Integrative Pediatric Oncology. Pediatric Oncology, A. Längler, P. Mansky, and G. Seifert, Eds., pp. 125-135, Springer, Berlin, Heidelberg, 2012.

[66] T. Amano, J. P. González-Varo, and W. J. Sutherland, "Languages are still a major barrier to global science," PLoS Biology, vol. 14, no. 12, p. e2000933, 2016.

[67] R. L. Perlman, "Mouse models of human disease: an evolutionary perspective," Evolution, Medicine, and Public Health, vol. 2016, 2016.

[68] V. W. Wong, M. Sorkin, J. P. Glotzbach, M. T. Longaker, and G. C. Gurtner, "Surgical approaches to create murine models of human wound healing," Journal of Biomedicine and Biotechnology, vol. 2011, Article ID 969618, 8 pages, 2011.

[69] T. Histing, P. Garcia, J. H. Holstein et al., "Small animal bone healing models: standards, tips, and pitfalls results of a consensus meeting," Bone, vol. 49, no. 4, pp. 591-599, 2011.

[70] Y. Xiong, A. Mahmood, and M. Chopp, "Animal models of traumatic brain injury," Nature Reviews Neuroscience, vol. 14, no. 2, pp. 128-142, 2013.

[71] A. H. Warriner, N. M. Patkar, J. R. Curtis et al., "Which fractures are most attributable to osteoporosis?," Journal of Clinical Epidemiology, vol. 64, no. 1, pp. 46-53, 2011.

[72] S. G. Hastrup, X. Chen, J. E. Bechtold et al., "Effect of nicotine and tobacco administration method on the mechanical properties of healing bone following closed fracture," Journal of Orthopaedic Research, vol. 28, no. 9, pp. 1235-1239, 2010.

[73] O. C. M. Pereira-Júnior, S. C. Rahal, P. Iamaguti, S. L. Felisbino, P. T. Pavan, and L. C. Vulcano, "Comparison between polyurethanes containing castor oil (soft segment) and cancellous bone autograft in the treatment of segmental bone defect induced in rabbits," Journal of Biomaterials Applications, vol. 21, no. 3, pp. 283-297, 2007.

[74] P. Aspenberg and O. Sandberg, "Distal radial fractures heal by direct woven bone formation," Acta Orthopaedica, vol. 84, no. 3, pp. 297-300, 2013.

[75] R. Hobbenaghi, P. Mahboob, S. Saifzadeh et al., "Retraction note: histopathological features of bone regeneration in a canine segmental ulnar defect model," Diagnostic Pathology, vol. 11, no. 1, p. 124, 2016.

[76] L. E. M. Padovan, D. G. E. Sousa, S. H. M. Padovan, G. J. P. L. D. Oliveira, R. D. da Silva, and M. Claudino, "Histological analysis of the use of biphasic ceramics based on hydroxyapatite and $\beta$-tricalcium phosphate in maxillary sinus floor elevation surgery: pilot study," Revista de Odontologia da UNESP, vol. 47, no. 2, pp. 63-68, 2018.

[77] S. Verma, "Role of Cissus quadrangularis in the treatment of osteoporosis: a review," Acute Medicine Research, vol. 1, 2018.

[78] M. H. Boskabady, S. Alitaneh, and A. Alavinezhad, "Carum copticum L.: a herbal medicine with various pharmacological effects," BioMed Research International, vol. 2014, Article ID 569087, 11 pages, 2014.
[79] V. Kant, A. Gopal, D. Kumar et al., "Curcumin-induced angiogenesis hastens wound healing in diabetic rats," Journal of Surgical Research, vol. 193, no. 2, pp. 978-988, 2015.

[80] R. Subramanian, M. Z. Asmawi, and A. Sadikun, "A bitter plant with a sweet future? A comprehensive review of an oriental medicinal plant: Andrographis paniculata," Phytochemistry Reviews, vol. 11, no. 1, pp. 39-75, 2012.

[81] S. Bais, N. S. Gill, N. Rana, and S. Shandil, "A phytopharmacological review on a medicinal plant: Juniperus communis," International Scholarly Research Notices, vol. 2014, Article ID 634723, 6 pages, 2014.

[82] I. Bensaid, F. A. Bekkara, I. A. El Haci, K. Belarbi, F. Beddou, and C. Bekhechi, "Phytochemical analysis and antioxidant properties of organic extracts obtained from Cynoglossum cheirifolium L," Oriental Pharmacy and Experimental Medicine, vol. 17, no. 4, pp. 381-387, 2017.

[83] M. Russo, C. Fanali, G. Tripodo et al., "Analysis of phenolic compounds in different parts of pomegranate (Punica granatum) fruit by HPLC-PDA-ESI/MS and evaluation of their antioxidant activity: application to different Italian varieties," Analytical and Bioanalytical Chemistry, vol. 410, no. 15, pp. 3507-3520, 2018.

[84] A. Lavola, M. Maukonen, and R. Julkunen-Tiitto, "Variability in the composition of phenolic compounds in winter-dormant Salix pyrolifolia in relation to plant part and age," Phytochemistry, vol. 153, pp. 102-110, 2018.

[85] N. J. Bristy, A. N. Hasan, M. N. Alam, T. B. Wahed, P. Roy, and K. K. Alam, "Characterization of antioxidant and cytotoxic potential of methanolic extracts of different parts of Aegle marmelos (L.)," International Journal of Pharmaceutical Sciences and Research, vol. 8, pp. 1476-1484, 2017.

[86] B. C. Bennett and M. J. Balick, "Does the name really matter? The importance of botanical nomenclature and plant taxonomy in biomedical research," Journal of Ethnopharmacology, vol. 152, no. 3, pp. 387-392, 2014.

[87] S. Sasidharan, Y. Chen, D. Saravanan, K. M. Sundram, and L. Yoga Latha, "Extraction, isolation and characterization of bioactive compounds from plants' extracts," African Journal of Traditional, Complementary and Alternative Medicines, vol. 8, no. 1, pp. 1-10, 2011.

[88] R. F. Sampaio and M. C. Mancini, "Estudos de revisão sistemática: um guia para síntese criteriosa da evidência científica," Revista Brasileira de Fisioterapia, vol. 11, no. 1, pp. 83-89, 2007.

[89] A. Liberati, D. G. Altman, J. Tetzlaff et al., "The PRISMA statement for reporting systematic reviews and meta-analyses of studies that evaluate healthcare interventions: explanation and elaboration," British Medical Journal, vol. 339, no. jul21 1, p. b2700, 2009.

[90] L. L. Miranda, Efeito de Extratos Vegetais no Reparo Ósseo e Cutâneo em Modelos Animais, Dissertation (Cellular and Structural Biology) -UFV, Viçosa, MG, 2018. 


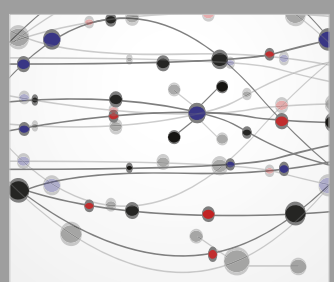

The Scientific World Journal
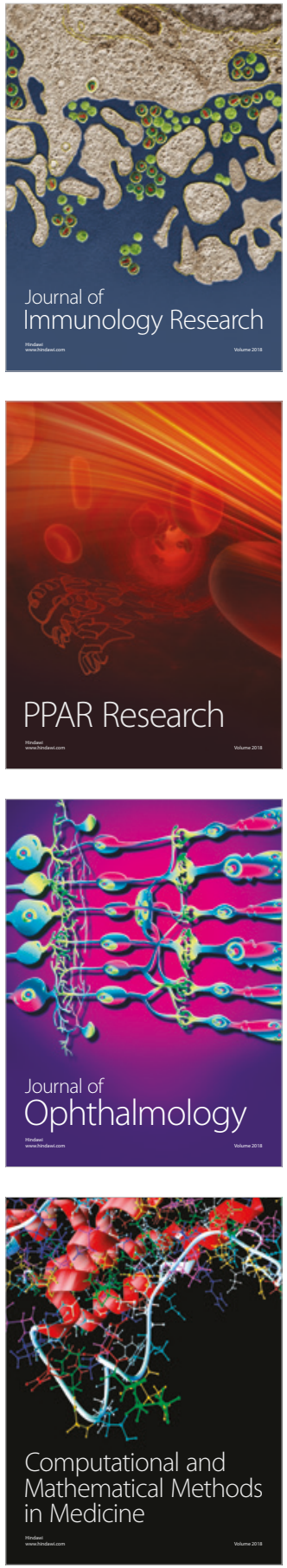

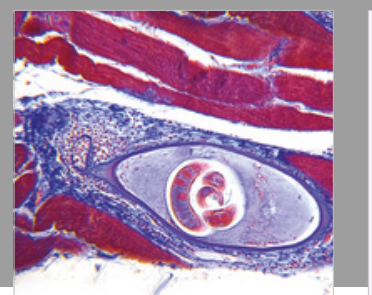

Gastroenterology Research and Practice

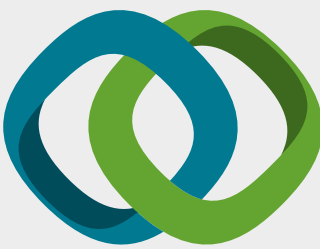

\section{Hindawi}

Submit your manuscripts at

www.hindawi.com
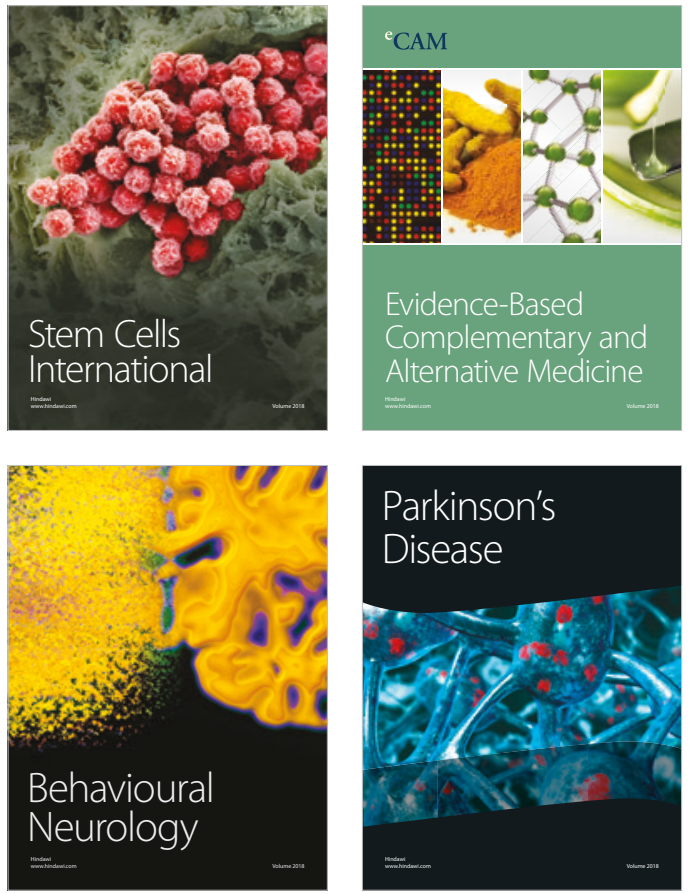

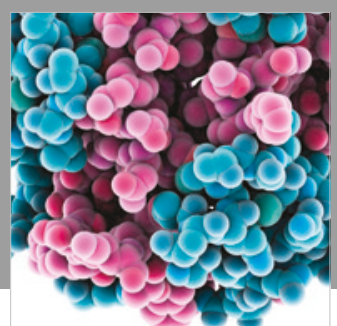

ournal of

Diabetes Research

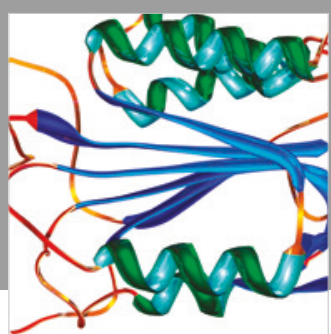

Disease Markers
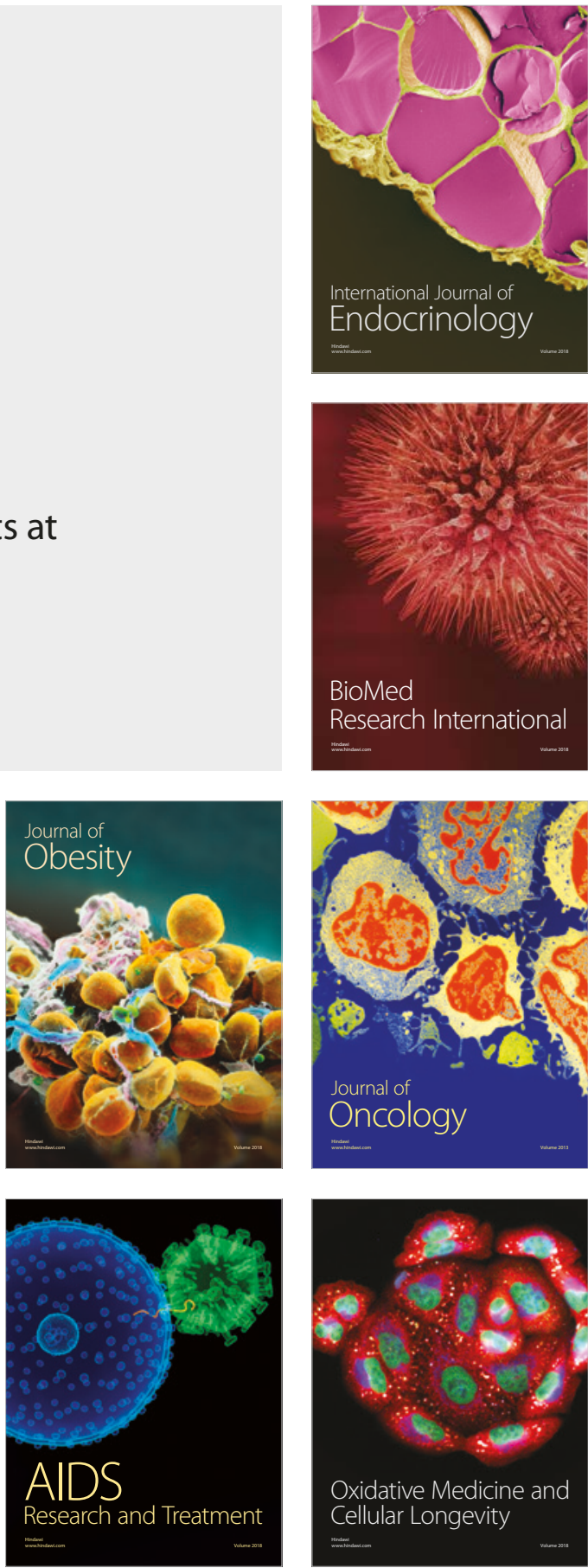